\title{
Simulated interactions of white-tailed deer (Odocoileus virginianus), climate variation and habitat heterogeneity on southern cattle tick (Rhipicephalus (Boophilus) microplus) eradication methods in south Texas, USA
}

\author{
Hsiao-Hsuan Wang ${ }^{1 *}$, Pete D. Teel ${ }^{2}$, William E. Grant ${ }^{1}$, \\ Greta Schuster ${ }^{3}$, and A. A. Pérez de León ${ }^{4}$
}

${ }^{1}$ Department of Wildlife and Fisheries Sciences, Texas A\&M University, College Station, TX 77843, USA

${ }^{2}$ Department of Entomology, Texas A\&M University, College Station, TX 77843, USA

${ }^{3}$ Department of Agriculture, Agribusiness and Environmental Sciences, Texas A\&M University-Kingsville, Kingsville, TX 78363, USA

${ }^{4}$ United States Department of Agriculture - Agricultural Research Service, Knipling-Bushland U.S. Livestock Insects Research Laboratory, and Veterinary Pest Genomics Center; Kerrville, TX 78028, USA

* Corresponding author. Tel.: 1-979-845-5702. E-mail address: hsuan006@ tamu.edu

\begin{abstract}
White-tailed deer (Odocoileus virginianus) are a host for cattle fever ticks (Rhipicephalus (Boophilus) sp.), which are vectors of the pathogens causing bovine babesiosis and anaplasmosis in cattle. Tick eradication efforts focused on cattle along the U.S.-Mexico border are high priority and the potential role of white-tailed deer in compromising these efforts is of great concern. We developed a spatially-explicit,
\end{abstract}


individual-based model to investigate the interactions of white-tailed deer, climate variation, and habitat heterogeneity on the efficacy of three standard tick eradication protocols: the application of acaricides to cattle every two weeks for (1) nine or (2) 12 consecutive months, or (3) the removal of cattle ("pasture vacation") for 12 consecutive months. We simulated the application of each of these eradication methods during each of three different annual temporal weather profiles for temperature, saturation deficit, and precipitation. Each of the methods suppressed the number of host-seeking larvae in the system to near zero. However, some host-seeking larvae remained, and white-tailed deer remained infested throughout the treatment period. Within 30 to 60 days after the termination of each treatment, tick infestations began to increase, and within 2 years after the initiation of each treatment, populations of host-seeking larvae had increased to pretreatment levels. Differences in treatment efficacy and tick population recovery rates were influenced by (1) the level of pre-treatment infestation, (2) weather conditions during the treatment year, and (3) weather conditions during the post-treatment recovery period. Treatment efficacy and tick population recovery also were influenced by the habitat heterogeneity since cattle and white-tailed deer have different habitat preferences. During treatment periods, white-tailed deer participated in creating tick refugia by dispersing engorged female ticks into, and collecting host-seeking larvae from, habitats favorable for the survival and development of off-host life stages. These refugia facilitated the recrudescence of infestations following the termination of treatment periods. Future applications to assess tick-host-landscape interactions and to consider alternative tick suppression tactics in integrated tick eradication systems are discussed. 
Key words: Agent-based, Individual-based, Modeling, Spatially-explicit, Stochastic. 


\section{Introduction}

Cattle fever ticks (CFT), Rhipicephalus (Boophilus) annulatus and R. (B.) microplus, invaded the United States of America (U.S.) when cattle were brought to the Americas and eventually became established throughout 14 states from Texas to Missouri and east to the Atlantic seaboard at the beginning of the $20^{\text {th }}$ century (Graham and Hourrigan 1977; Barré and Uilenberg 2010). These one-host ticks (Fig. 1) pose a significant threat to the economic security of the U.S. cattle industry as vectors of Babesia bigemina and B. bovis, which cause bovine babesiosis, and Anaplasma marginale that causes anaplasmosis (Pérez de León et al. 2014a; Aubry and Geale 2011). The Cattle Fever Tick Eradication Program established between the federal government and affected states was successful in eradicating these ticks in the U.S., and thus the risk posed by bovine babesiosis, by mid-century in part because tactics and strategies for tick suppression could be cattle-centric (Graham and Hourrigan 1977). These ticks and pathogens remain endemic in neighboring Mexico and pose continuous risks to the U.S. livestock industry (Estrada-Pena et al. 2006; Lohmeyer et al. 2011; Pérez de León et al. 2014b). The eradication program operates a permanent quarantine zone in south Texas along the border with Mexico to manage these risks (Fig. 2).

The presence of alternate or secondary hosts poses significant challenges to the eradication program (Pérez de León et al. 2010). White-tailed deer, Odocoileus virginianus, (hereafter referred to as "deer") is a recognized host for both tick species (George 1989). Deer were a source of food and commercial products to early explorers and settlers, thus their populations diminished significantly in the 1700-1800s (Rue 1978). Conservation programs initiated in the mid- $20^{\text {th }}$ century reintroduced and 
successfully re-established populations throughout the original range of CFT with at least 3 million deer estimated to exist in Texas in 2011 (Graham and Hourrigan 1977; Vercauteren et al. 2011; Hygnstrom et al. 2014). Deer and cattle now co-habit rangeland landscapes throughout south Texas and northern Mexico, and both species are considered economic assets to ranching and/or recreational hunting enterprises (Cooper et al. 2008). However, as is the case with other diseases, the deer-cattle interface poses risks for tick re-invasion and re-emergence of bovine babesiosis in the U.S. (Miller et al. 2013; Esteve-Gassent et al. 2014). Short- and long-distance movements of CFT within Texas and across the U.S.-Mexico border determined by genotyping populations reflected the scale of potential tick dispersal by deer beyond the permanent quarantine zone (Busch et al. 2014).

The involvement of deer as a complicating factor for the eradication program was considered by the 1970's (Gray et al. 1979) when traditional eradication protocols including the systematic dipping of cattle, or vacating cattle from infested premises were failing. Epidemiological analysis of tick outbreaks indicated that deer compromised eradication efforts by sustaining and/or re-infesting premises (Pound et al. 2010).

Three tactics for CFT suppression on deer have been developed and implemented (Pound et al. 2010) that rely upon deer attraction to corn as bait. Variation in baitstation design permit access to systemically-active acaricides on corn-bait, or permit self-treatment with acaricides on paint rollers when the animal is feeding, or permit the mechanical attachment of slow-release acaricide-impregnated collars as the animal is feeding. Vaccination of cattle and deer against CFT is being considered (Miller et al. 
2012; Estrada-Pena et al. 2014). However, spatial-temporal dynamics of ecological, climatological and operational conditions associated with tick elimination on deer have not been thoroughly investigated.

Methods employed by the eradication program to treat cattle on infested premises require treatment of the entire herd at 2-week intervals with acaricide assuring $100 \%$ CFT elimination (Miller et al. 2005). The practice of vacating pastures remains an option in the program. Treatment of deer with acaricide in infested landscapes based on animal-host targeted approaches is inherently less than $100 \%$ effective (Currie 2013), in that not all animals come to the treatment stations, and not all treated animals receive effective dosages (Grear et al. 2014; Pound et al. 2012). The potential for tick refugia persists, in part due to such factors as variation in spatial characteristics of optimal tick habitats and shifts in landscape usage by cattle and deer (Cohen et al. 1989). Infestations that return or persist despite extensive efforts to eradicate CFT are further expensive to eliminate and suggest that the interplay between tick-deer-habitat interactions and weather and landscape variation may drive the persistence of CFT in the environment.

The aim of this project is to apply simulation modeling as an investigative tool to assess CFT outbreak dynamics and spatial attributes in tick-host-landscape systems involving multi-host species, and to test the efficacy of proposed tactics and strategies for sustainable eradication (Miller et al. 2012; Pérez de León et al. 2012). We hypothesize that interactions of climatic variation and habitat heterogeneity on tickinfested rangeland supporting deer and cattle will produce variable outcomes following implementation of eradication program methods directed at cattle. Explicit 
consideration of these interactions should aid in designing future tactics and strategies for tick suppression where multiple host-species must be considered.

Here, we describe a spatially-explicit, individual-based, stochastic model developed to assess the interactions of climate and multiple tick hosts on south Texas rangelands. More specifically, we use the model to investigate the role of deer in sustaining CFT populations in pastures of mixed rangeland-habitat types grazed by cattle, which are subject to climatic variation over years. We first describe the model following the protocol suggested by Grimm et al. $(2006,2010)$ for describing individual-based models. We then calibrate several versions of the model representing different assumptions regarding CFT densities that would be maintained by deer in the absence of cattle. We next evaluate the model with regard to sensitivity of simulated densities of on-host CFT to the uncertainties embodied in these assumptions. Finally, we simulate CFT population dynamics in response to different eradication tactics with each version of the model.

\section{Model description}

In addition to the following ODD (Overview, Design concepts, and Details) model description protocol suggested by Grimm et al. $(2006,2010)$, we also provide a summary of model parameter values and equations in the Appendix.

\subsection{Purpose}

The purpose of the model is to examine how the presence of deer and climatic variation affects the efficacy of common eradication methods for CFT in south Texas, USA, specifically the removal of cattle from the system ("pasture vacation") and the application of acaricides. 


\subsection{Entities, state variables, and scales}

Entities include (1) 900, square, 1-ha habitat cells arrayed as a torus (i.e., the simulated landscape "wraps" from right to left and from top to bottom), and (2) a specified number (up to several hundred) of individual mammalian hosts (cattle and deer) of cattle fever ticks. State variables, or attributes, of habitat cells include: location (x and y coordinates), habitat type (mesquite savanna, mixed-brush savanna, or open un-canopied grassland), and current numbers of tick eggs, larvae, and engorged (fed) adults in each weekly age-class located in the cell, as well as the current numbers of cattle and deer located in the cell. Attributes of hosts include location of the center of their activity range ( $\mathrm{x}$ and $\mathrm{y}$ coordinates), current location ( $\mathrm{x}$ and $\mathrm{y}$ coordinates), habitat type of current location (mesquite savanna, mixed-brush savanna, or open un-canopied grassland), relative habitat preferences (a value between 0 (low preference) and 1 (high

preference) for each habitat type), size of activity range (ha), relative number of larvae they can carry at any given time (1.0 for cattle, 0.1 for deer), and numbers of larval, nymphal, and adult ticks in each age-class they currently are carrying (on-host ticks advance through 30 age classes each week). Global variables representing environmental conditions, which are updated weekly over a 7-year period, include temperature $\left({ }^{\circ} \mathrm{C}\right)$, saturation deficit $(\mathrm{MB})$, and a precipitation index $(\mathrm{cm})$.

The determination of temporal and spatial scales was based on the ecology of the organisms involved (Fig. 1), the level of detail contained in available information, and computational considerations. Weekly time steps allow adequate representation of the effects of temperature, saturation deficit, and precipitation on the various off-host stages of the tick life cycle (Mount et al. 1991). Thirty time steps per week provide adequate 
representation of the spatial-temporal redistribution of ticks which result from the 30 movements per week of each host about the landscape (see Section 2.7.3). A 7-year simulation period provides adequate time for both the abundance and distribution of ticks to respond to the tick control methods simulated in the model. A spatial resolution of 1 ha provides adequate detail to represent model processes and to present model results, and also is consistent with the general information available for landscape classification (Horton, 2003) and the description of host habitat use (Cooper et al. 2008; Cohen et al. 1989). More detailed information describing habitats and habitat use, when available, is too site- and species- specific to be generally applicable. The spatial extent represented by 900 1-ha habitat cells arrayed as a torus is adequate to describe landscape structure and host movements typical of south Texas and to demonstrate model application under the particular scenarios for the eradication methods considered in this paper.

\subsection{Process overview and scheduling}

The model was programmed and simulations were executed in NetLogo (Wilensky 1999, http://ccl.northwestern.edu/netlogo/). Simulation results were exported by NetLogo as text files, which were imported by Excel@ (Microsoft, 2003) for archiving, statistical analyses, and temporal graphics. The Excel@ data files were imported by ArcMapTM 9.1 (ESRI, 2005) for spatial statistics and visualization of spatial patterns. During each simulation, the NetLogo program first initializes the system by creating and assigning attributes to the landscape cells and the individual hosts (Fig. 3). The program then reads input data in the form of time series of values representing the climatic conditions under which the simulation will be run. Next, the 
program iteratively executes the seven submodels described below, which are nested in two loops. At the beginning of the first time step of each simulated week, the program (a) executes tick control of applicable (see Section 2.7.1 below), (b) updates climatic conditions and recalculates associated off-host tick survival and development rates (see Section 2.7.2 below) and (c) updates attributes of landscape cells representing the number of ticks in each off-host developmental phase (see Section 2.7.3 below). Then, 30 times during the week, the program iteratively executes submodels (d) through (f). The order in which individual hosts are selected to perform the activities within each submodel is randomized at the beginning of each execution of the submodel. During each iteration, the program first (d) calculates the number of off-host larvae collected by each host and updates the corresponding attributes of landscape cells (off-host larvae) and individual hosts (on-host larvae) (see Section 2.7.4 below). Then it (e) calculates the survival and development of on-host ticks (larvae, nymphs, and adults), calculates the number of engorged female ticks deposited by each host in each landscape cell, and updates the corresponding attributes of landscape cells (engorged female ticks) and individual hosts (on-host larvae, nymphs, and adults) (see Section 2.7.5 below). Then it (f) moves each host to a new landscape cell within their activity range and updates the corresponding attributes of landscape cells (number of hosts) and individual hosts (current location and habitat type) (see Section 2.7.6 below). Finally, at the end of the last time step of each simulated week, the program (g) writes output to text files, which includes current values of climatic conditions, landscape attributes, and host attributes, as well as system-level statistics (e.g., mean (SD), maximum and minimum values) summarizing landscape attributes and host attributes (see Section 2.7.7 below). 


\subsection{Design concepts}

\subsubsection{Basic principles}

The biological concept underlying the model design is that the CFT life cycle is influenced by climatic conditions, landscape structure, and composition of the host community. Survival and development of off-host stages are dependent on the temperature and relative humidity in habitat-types to which they are exposed as a consequence of host-driven dispersal of gravid females. Completion of the tick life cycle depends on larvae encountering an appropriate host, which is influenced by species abundance and composition of the host community and habitat preferences of potential host species. With the goal of providing a useful tool for exploring potential effects of deer on the efficacy of controlling CFT on cattle, the model has been designed to represent explicitly the effects of climatic variability, landscape heterogeneity, and variable host community composition on tick population dynamics. Climatic variability is represented via input data (including time series of historical data representing weekly temperatures, saturation deficits, and precipitation). Landscape heterogeneity is represented via creation of a spatially-explicit hypothetical landscape consisting of three different habitat types. Variable host community composition is represented via creation of individuals representing two different host species, which move about the landscape, collecting and depositing ticks. Individual hosts enter and are removed from the system during each simulation such that the number of individuals of each species varies through time.

\subsubsection{Emergence}


Spatial and temporal patterns of abundance of off-host tick larvae emerge as system-level properties as a result of equations describing rates of off-host tick development and survival, and rules governing the movements of hosts within the landscape. Rates of off-host tick development and survival depend on the temporallyvariable climatic conditions (temperature, saturation deficit, precipitation). Movements of hosts within the landscape depend on the spatially-heterogeneous distribution of habitat types, with probabilistic movement rules favoring selection of landscape cells with the habitat types more preferred by the host. The mean numbers of adult ticks per individual of each host species also emerge as system-level properties. However, the general temporal patterns associated with these means can be anticipated based on the temperature-dependent seasonal variation in the activity level of off-host (host-seeking) tick larvae, the fixed survival rates of ticks on hosts, and the fixed maximum limits on the number of larvae allowed on hosts.

\subsubsection{Adaptation}

Individual hosts do not possess adaptive traits, the rules for their behavior (movement and collection and deposition of ticks) are fixed.

\subsubsection{Objectives}

Individual hosts do not adapt their behavior to achieve specific objectives.

\subsubsection{Learning}

Individual hosts do not learn, that is, they do not change their behavior as a result of past experience.

\subsubsection{Prediction}


Individual hosts do not predict the future, that is, they do not estimate future conditions nor judge the consequences of their behavior.

\subsubsection{Sensing}

Individual landscape cells sense (are "aware" of) their habitat type, which affects the survival rates of off-host ticks located in the cell. Individual hosts sense the location of the center of their activity range, the size of their activity range, their habitat preferences, the proportions of landscape cells of each habitat type within their activity range, and the maximum number of larvae they can carry at any given time. For both landscape cells and individual hosts, the mechanisms by which this sensing occurs is implicit, that is, there are no explicit rules governing the acquisition of this information.

\subsubsection{Interaction}

Interactions between landscape cells and individual hosts occur implicitly via the collection and dispersal of ticks among the landscape cells within the activity ranges of individual hosts. Interactions among individual hosts occur implicitly in that tick larvae collected by one host cannot be collected by other hosts.

\subsubsection{Stochasticity}

During initialization of the model, the program probabilistically selects the permanent center of the activity range of each individual host based on the relative habitat preferences of the host, and places the host in that center habitat cell. During simulations, the next habitat cell to which a host moves is selected probabilistically based on the relative habitat preferences of the host. This stochasticity results in a probabilistic distribution of hosts available to off-host tick larvae (host-seeking larvae), and a probabilistic distribution of engorged female ticks deposited by hosts. Thus, 
stochasticity within the model causes host activities to occur with specified mean frequencies within the constraints imposed by the general structure of the landscape.

\subsubsection{Collectives}

The model groups individual hosts into two collectives: cattle and deer.

Individuals within each collective share common species-specific attributes including relative habitat preferences, size of activity range, and relative number of larvae they can carry at any given time.

\subsubsection{Observation}

The model records weekly values for the number of eggs, larvae, and engorged adults in each habitat cell, and the number of ticks in each life stage on each host. These data are used primarily for verifying that model code is functioning appropriately. Summary output data collected from the model include the system-level densities of hostseeking larvae, the mean number of adult ticks on cattle, and the mean number of adult ticks on deer.

\subsection{Initialization}

The program creates a hypothetical landscape typical of south Texas consisting of $30 \%$ mesquite dominated community (referred to as mesquite), 30\% mixed-brush dominated community (referred to as mixed-brush), and $40 \%$ uncanopied grass (referred to as open grass), based upon the succession and management of thorn shrublands in the region (Archer et al. 1988; McMahan and Inglis 1974). Thus the hypothetical landscape for each simulation consists of 270 ha of mesquite, 270 ha of mixed-brush, and 360 ha of open grass. The spatial distribution of these habitat types across the landscape does not change during a simulation run, but differs from simulation to simulation. For each 
simulation, the landscape is "grown" from 10 initial patches (grid cells) positioned at xy coordinates 3-3, 3-26, 7-11, 7-19, 15-5, 15-24, 20-11, 20-19, 26-3, and 26-26. Each of these patches is randomly assigned a habitat type ( 3 mesquite, 3 mixed-brush, and 4 open grass). Each patch then, in turn, expands into an adjacent, unoccupied cell until the entire landscape has been filled, that is, until each grid cell has been assigned a habitat type. If it is impossible to obtain the desired landscape composition in any given intent, the procedure is repeated until the desired landscape composition is obtained. When the desired landscape is obtained, each grid cell is assigned 100,000 larvae. The program creates 669 individuals to represent tick hosts. One hundred thirteen individuals are designated as cattle and 556 individuals are designated as deer. These numbers represent typical cattle stocking rates under continuous grazing $(0.125$ individuals per hectare, Cohen et al. 1989; Cooper et al. 2008), and deer densities (0.6175 individuals per hectare; Kie and Bowyer 1999) in south Texas. Cattle are assigned an activity range of 300 ha (Howery et al. 1996), relative habitat use preferences for mesquite, mixed-brush, and open grass of 0.3, 0.1, and 0.6, respectively, and the relative number of larvae they can carry at any given time is set at 1.0 (ten times greater than deer). Deer are assigned an activity range of 675 ha (Hellickson et al. 2008), relative habitat use preferences for mesquite, mixed-brush, and open grass of 0.2, 0.4, and 0.4, respectively (McMahan and Inglis 1974; Cohen et al. 1989; Cooper et al. 2008), and the relative (to cattle) number of larvae they can carry at any given time is set at 0.1 (Cooksey et al. 1989). Each host is assigned 0 on-host ticks (0 larvae, 0 nymphs, 0 adults). Numbers of cattle and deer remain constant during each simulation, as do sizes of activity ranges and habitat use preferences. Each host is placed in a 
landscape cell that is chosen probabilistically based on its relative habitat use preferences. This initial cell becomes the permanent center of the host's activity range.

\subsection{Input data}

The program reads 7-year time series (1994-2000) of historical data representing (1) weekly temperatures $\left({ }^{\circ} \mathrm{C}\right),(2)$ weekly saturation deficits (MB), and (3) weekly values of an index based on precipitation $(\mathrm{cm})$ for Corpus Christi, Texas, USA. These data were obtained from the Southern Climate Center, Baton Rouge, Louisiana, USA and were used to represent these climatic conditions during simulations (Fig. 4a). The Corpus Christi area was infested in the past and comprises suitable climatic conditions for cattle fever ticks (Estrada-Pena and Venzal 2006; Giles et al. 2014). The period from 1994 to 2000 included both relatively wet and relatively dry years.

\subsection{Submodels}

\subsubsection{Execute tick control if applicable}

At the beginning of each week, the program checks to see if tick control should be applied and, if so, executes the tick control method being simulated. Tick control methods include: (1) the application of acaricides to cattle every 2 weeks for 9 consecutive months, (2) the application of acaricides to cattle every 2 weeks for 12 consecutive months, and (3) the removal of cattle from a pasture ("pasture vacation") for 12 consecutive months. Assessment criteria include: (1) the relative density of hostseeking larvae in the environment, and the number of (2) adult ticks on cattle and (3) on deer prior to, during, and for several months following the application of each control method. The application of acaricides to cattle is represented by setting the values of the host attributes representing the number larval, nymphal, and adult ticks to zero. 
Pasture vacation is represented by temporarily removing cattle from the system. (In NetLogo, the individual hosts representing cattle "die" and new individuals representing cattle are "created" 12 months later.)

2.7.2 Update climatic conditions and recalculate associated off-host tick survival and development rates

At the beginning of each week, the program updates temperature, saturation deficit, and the precipitation index based on values in the corresponding time series of inputs (Section 2.6). Based on these new environmental conditions, the program recalculates off-host survival and development rates for tick eggs, larvae, and engorged adults in each type of habitat, as well as the relative rate of host-seeking activity of offhost larvae, based on information presented by Mount et al. (1991). The program also calculates the number of eggs laid per ovipositing female as a function of temperature and the type of host from which the female obtained her blood meal based on information presented by Cooksey et al. (1989). The program calculates development rates of eggs and engorged (fed, after blood meal) adults as functions of cumulative “degree-weeks" of temperature; survival rates of eggs and off-host engorged adults as functions of current (weekly) temperature, saturation deficit, and precipitation, as modified by habitat type; and relative rates of host-seeking activity of off-host larvae (the proportion of off-host larvae that potentially could encounter and attach to a host) as functions of current (weekly) temperature following Mount et al. (1991) (Appendix). 2.7.3 Update attributes of landscape cells representing number of ticks in each off-host developmental phase 
At the beginning of each week, the program updates each landscape cell in terms of (1) the number of tick eggs, larvae, and engorged adults that have survived, (2) the number of eggs that have developed into larvae, (3) the number of engorged (female) adults that have laid eggs and died, and (4) the number of eggs laid. The survival of eggs, larvae, and engorged adults depends on temperature, saturation deficit, and the precipitation index, as well as the habitat type of the landscape cell following Mount et al. (1991) (Appendix). The development of eggs and engorged adults depends on temperature following Mount et al. (1991), and the number of eggs laid per engorged (female) adult depends on the species of the host from which the female obtained her blood meal following Cooksey et al. (1989) (Appendix).

\subsubsection{Calculate number of off-host larvae collected by hosts and update corresponding} attributes of landscape cells and individual hosts

Thirty times during each week, preceding each of the 30 rounds of host movements (see Section 2.7.6 below), the program calculates the number of off-host larvae that are collected by each host from each landscape cell and updates the number of larvae in each cell and the number of larvae on each host. Each individual host has a probability of collecting larvae that depends upon the abundance and relative activity level of larvae in that cell, with an upper limit on the number of larvae that can be collected determined by the number of larvae already on the host. The relative activity level of off-host larvae depends on temperature following Mount et al. (1991) and the maximum number of larvae allowed on a host depends on the species of the host (see Section 3 below). 
2.7.5 Calculate survival and development of on-host ticks, calculate number of on-host ticks deposited by hosts, and update corresponding attributes of landscape cells and individual hosts

Thirty times during each week, preceding each of the 30 rounds of host movements (see Section 2.7.6 below) and following the collection of off-host larvae during each round (see Section 2.7.4 above), the program calculates the survival and development of the larval, nymphal, and adult ticks on each host, and updates the corresponding attributes of each host. The duration of on-host life stages is one week for larvae, one week for nymphs, and one to two weeks for adults, following Mount et al. (1991), and the on-host survival rates for larvae, nymphs, and adults also follow Mount et al. (1991) (Appendix). The program then deposits 10\% of the adult ticks that have been on a host for at least three weeks into the landscape cell in which the host currently is located and updates the corresponding attributes of the host and the landscape cell. Thus members of any given cohort of on-host adult ticks are deposited as engorged adults into up to 30 different landscape cells during the 30 host movements that occur during the last week that the adults are on the host.

2.7.6 Move hosts within the landscape and update corresponding attributes of landscape cells and individual hosts

Thirty times during each week, following the collection, on-host survival and development, and deposition of ticks during each of the 30 rounds, the program moves each host within the landscape. The landscape cells visited are selected probabilistically from those within the activity range of the host based on the habitat preferences of the host and the proportion of the different habitat types within the activity range. The 
program code that executes host movements is provided in the Appendix. Note that, since habitat cells within the simulated landscape are arrayed as a torus, the activity ranges of individuals are not limited by the edges of the $30 \times 30$ cell grid used for visual displays of the landscape. For example, if an individual's activity range is centered near the right-hand edge of the visual display grid, it "wraps around" onto the left-hand portion of the visual display grid. Thus, host movements are unconstrained by an "edge effect."

2.7.7 Write output summarizing landscape attributes, host attributes, and system-level statistics

At the end of each week, the program writes to text files summaries of climatic conditions (temperature, saturation deficit, precipitation index), selected attributes of landscape cells (density of off-host larvae), hosts (number of on-host adult ticks), and system-level statistics (mean density of off-host larvae in the system and in each habitat type, mean number of on-host adult ticks per individual for each host species).

\section{Model calibration}

Maximum allowable tick loads of hosts were calibrated under the assumptions that (1) the maximum tick load that an individual deer can carry is approximately onetenth that of an individual cow, based upon their comparatively smaller body size and greater ability to groom off attached ticks (Cooksey et al. 1989), and (2) that deer appear to sustain CFT populations in the absence of cattle over long periods of time (Pound et al. 2010). These assumptions were represented in the model by establishing a calibration constant $(k)$ that limits the maximum number of CFT larvae allowed on an 
individual host at any one time, thus imposing a variable upper limit on the number of ticks that can be collected by any given host at any given time, which depends on the number of ticks already on that host. Twenty Monte Carlo simulations were performed in which we sequentially reduced the value of $k$ from 10,000 until, at $k<100$, deer could no longer sustain the simulated CFT population in the absence of cattle. With $k=$ 100 , the mean number of adult ticks on deer varied seasonally from 0 for short periods during the coldest months (January and February) to 4.5 to 4.8 during most of the rest of the year, and was sufficient to sustain the CFT population without cattle (Fig. 4). There were no qualitative differences in seasonal or year-to-year trends in on- or off-host tick abundances produced by values of $k>100$. But, absolute abundances of both on- and off-host ticks increased with increasing values of $k$.

\section{Model application}

We evaluated the interactions of cattle, deer and habitat under variable climatic conditions by simulating 3 eradication methods: (1) the application of acaricides to all resident cattle every 2 weeks for 9 consecutive months, where efficacy was $100 \%$ against CFT at the time of each treatment (DipNine), (2) the application of 100\% efficacious acaricides to all resident cattle every 2 weeks for 12 consecutive months (DipTwelve), and (3) the removal of all cattle from a pasture for 12 consecutive months (CattleOff), then restocking the pasture with the same number of non-infested cattle. The application of each of these 3 methods was simulated starting in January 1 of years 1995, 1996, and 1997, using weather data for Corpus Christi, TX, as described above. These treatment years were selected because they present different temporal weather 
profiles for temperature, saturation deficit, and precipitation for the treatment period of 12 months, and were correspondingly flanked by different profiles in 1994 and 1998.

We ran 3 Monte Carlo simulations of each of these 9 scenarios with the model parameterized and calibrated as described in Sections 2 and 3 above. During each simulation, we monitored (1) the relative density of host-seeking larvae in the environment, (2) the number of adult ticks on cattle, and (3) the number of adult ticks on deer prior to, during, and after treatment. We compared overall treatment efficacy among the scenarios based on the mean number of "host-seeking larval weeks" accumulated during the 2 years immediately following the week of treatment application using Duncan's multiple-range tests. Three Monte Carlo simulations of each scenario allowed detection of a difference of 6667 "host-seeking larval weeks" among treatments with a Type I error $=0.05$ and a Type II error $=0.01$, or a difference $\approx 2.3 \%$ in the overall mean number of "host-seeking larval weeks."

To examine the sensitivity of simulation results to changes in the values of key model parameters, we conducted a sensitivity analysis in which we varied parameters representing landscape structure, deer density, and the calibration constant (k, which imposes an upper limit on the number of ticks that can be collected by any given host at any given time). We created 9 new versions of the model in which we represented the landscape as consisting of (1) all good, (2) all fair, and (3) all poor habitat; fixed deer densities at (4) 1.235 (double baseline), (5) 0.30875 (half baseline), and (6) 0 individuals / ha; and set the value of $\mathrm{k}$ at (7) 90 (90\% of baseline), (8) 110 (110\% of baseline), and (9) 120 (120\% of baseline). Using each of these 9 new versions of the model, we repeated the original experimental design, again comparing overall treatment 
efficacy among the scenarios based on the mean number of "host-seeking larval weeks" accumulated during the 2 years immediately following the week of treatment application using Duncan's multiple-range tests.

\section{Results}

\subsection{Results of model evaluation}

Simulations summarized in Figure 4 illustrate that the system comprised of rangeland, cattle, and/or deer provide a mechanism for recurrent CFT infestations throughout the 7-year period. Alignment of the 7 annual weather profiles (Fig 4a) with respective simulated populations of host-seeking larvae (Fig 4b), adult ticks on cattle (Fig 4c), and deer (Fig 4d) provides a basis for evaluating the dynamics of CFT infestations. With the introduction of cattle to the system $(k=100)$, the mean number of adult ticks on deer varied seasonally between 0 and 5 with declines occurring during coldest months, while the mean number of adult ticks on cattle varied seasonally from 0 to $\approx 50$, exhibiting the same seasonality. Declines in infestations for each host species during winter months reflect tick responses to low temperatures that retard oviposition, prolong egg incubation, larval emergence and host-seeking activity. Figures $4 \mathrm{~g}$ and $4 \mathrm{~h}$ for cattle and deer, respectively, show expanded detail of the simulations in the year 1996 for host infestations in relation to weather and the impact of winter temperatures from December to March. Published data comparing tick loads on both cattle and deer co-habiting south Texas rangelands do not exist in part due to quarantine regulations. Thus, interpretations of simulation results must be guided by comparative reasoning. Currie (2013) summarized a 2-year study in Zapata County, Texas where 244 deer captured and inspected on multiple dates from February to September in 2010 
and 2011 showed a mean infestation prevalence of 67\% (range 20-100\%), and an average infestation of 13 adult CFT per deer.

The mean density of host-seeking larvae (Fig 4b) exhibits oscillations consistent with their exposure to environmental conditions during the off-host phase of the life cycle. On 4 occasions, density of host-seeking larvae exceeded 8,000 per hectare (see notations 1, 2, 3, and 4 on Fig 4b), each of these occurring in late fall/early winter following a period of increased precipitation and decreasing saturation deficit. On 3 occasions, density of host-seeking larvae declined below 2,000 per hectare (see notations 5, 6, and 7 on Fig 4b). Two of these (notations 5 and 6) occurred in response to periods of dry and cold weather during the preceding 6-8 months, while the third (\#7) occurred in response to an extended period of excessively dry weather.

Annual variation in host seeking larvae appears to follow a bimodal response (Fig 4e and 4f) with a spring increase, summer decline, followed by fall increase and winter decline, which is similar to that described to occur in New Caledonia (Daynes and Gutierrez 1980). These oscillations appear to result from periods of precipitation and low saturation deficit favorable for larval survival (typical seasonal occurrence in spring or fall), with periods of high temperature and saturation deficit (typical of summer), and with periods of low temperature sometimes compounded by conditions of precipitation and saturation deficits (typical of winter). The amplitude and duration of these annual oscillations in host-seeking larvae varies in response to the complexities of these parameters, and in these simulations track consistently. Published data do not exist for densities of host-seeking larvae on south Texas rangelands. However, Phillips et al. (2014) surveyed south Texas rangeland habitats for CFT larvae and established linkages between larval distribution and population changes associated 
with vegetation-types and climatic conditions. Simulation results presented by Mount et al. (1991) were interpreted under the same constraints. They estimated larval densities for south Texas of approximately 200,000 per hectare; these simulations also estimated somewhat less than 200 adult ticks per cow and no other hosts were included in that model. The influence of landscape features on the annual variation of host-seeking larvae determined by ecological factors was also documented in Puerto Rico (UrdazRodríguez et al. 2012).

Simulation of host-habitat relationships of rangeland usage by cattle and/or deer enabled the visualization of predicted spatial patterns of host-seeking larvae resulting from tick dispersal by hosts interacting with habitat suitability for off-host tick development and survival (Fig. 5). The 3 habitat-types (Fig. 5a) were disproportionately used by each host, which is illustrated separately for cattle in Figure 5b, and for deer in Figure 5c. Heavier usage of open grass interstitial zones and mixed-brush by cattle (Fig. 5b), and along edges of mixed-brush and mesquite by deer produced a mosaic pattern of host-seeking larvae in Figure 5d with the most dense tick populations in mesquite zones and along edges of mixed-brush. Figure 5e illustrates the preponderant contribution of host-seeking larvae by cattle alone (a sub-set of Figure 5d) and that the resulting patterns are essentially the same. This reflects the combined product of a larger number of hosts (number of cattle/ha) producing larger numbers of ticks per animal with habitat preferences ranging from good to poor. In contrast, deer habitat use in Figure $5 \mathrm{c}$ resulted in the greatest contribution to host-seeking larvae in mixed-brush and mesquite zones by a smaller number of animals per hectare that produce much smaller numbers of ticks per animal. Cohen et al. (1989) and Cooper et al. (2008) described cattle and deer habitat-use as being driven by the 
availability and proximity of water, as well as forage grasses or browse and forbs, and by corresponding needs for canopied vegetation to provide cover and heat-stress relief.

\subsection{Results of model application}

Each simulated eradication method substantially suppressed the number of host-seeking larvae in the system (Fig. 6) whether by systematic dipping of cattle for 9 or 12 months, a process permitting cattle to graze and acquire ticks that are killed by acaricide treatment, or by simply removing the cattle as a host in the system for 12 months. Although the populations of host-seeking larvae were suppressed to near zero, the system remained infested through each treatment year. Regardless of the treatment approach, deer remained infested throughout the treatment period (data not shown). Deer infestations tended to remain equal to pretreatment levels, but a minor decline in the number of CFT on deer was noted near the end of each treatment period when co-habiting cattle were treated systematically with acaricides for 9 or 12 months. This was more pronounced for treatments commenced in 1996 and 1997, than those started in 1995. Declines in deer infestations reflect the combined effects of: 1) CFT larvae removal from the landscape by cattle that serve as a "sponge" or "trap" for ticks subsequently killed by dipping treatment, and 2) apparently harsher summer conditions for larval survival in 1996 and 1997. Within 30 to 60 days of ending each treatment method, CFT infestations began to increase on both cattle and rangeland. CFT populations were back in equilibrium with pretreatment levels within 2 years of the initiation of each eradication method.

Results of simulations for populations of host-seeking larvae are depicted in Figure 6. Differences in treatment efficacy and recovery rates appeared to be influenced by: 1) the level of pre-treatment infestation, 2) weather conditions during the treatment year, and 3) weather conditions during post-treatment recovery. Treatment efficacy and recovery are also reflected 
and partially explained by the spatial distributions of host-seeking larvae during the selected months (Fig. 7).

Treatment year 1995 began with a host-seeking larval population over 8,000/ha, which declined to near zero in 6 months (Fig. $6 \mathrm{~b}$ and f). Increasing precipitation in the last quarter of 1995 appeared to boost the population recovery of host-seeking larvae following treatment that year. The recovery from the 9-month dipping treatment exceeded 4,000 host-seeking larvae/ha before the end of the treatment year (Fig 6f, notation 1), which is shown spatially in Figure 7 , 1995 December after-treatment panel. This recovery was supported by beneficial precipitation and decreasing SD values in the last quarter of 1995 (see weather detail Fig 6e). Recovery from the 12-month period of cattle dipping and pasture vacation increased during the spring of 1996 along with a second progressive increase in recovery from the 9-month treatment (Fig 6f, notation 2). Response to the 12-month treatment period was essentially equal in rate and spatial distribution. Recovery from all 3 eradication methods exceeded 6,000 host-seeking larvae/ha by the end of 1996 (Fig 6f, notation 3). This level represents approximately $75 \%$ of the pretreatment infestation. Weather conditions for south Texas in 1996 were particularly dry with long periods of high temperature, both of which would retard CFT survivorship in pastures.

Treatment year 1996 began with a host-seeking larval population at 10,000/ha (Fig. 6c and g). This was the highest starting larval population of the 3 years modeled. It appears beneficial weather in the last quarter of 1995 promoted that larval population peak. This is reflected spatially in Figure 7 by the expanse of dense larval distribution reflected in the December 1996 before treatment panel. Cattle dipping for 9-months did not suppress the hostseeking larval population below 1,500/ha. Larval population recovery was well underway in the last months of 1996 (Fig 6g, annotation 1), ultimately reaching approximately 6,000/ha by the 
end of 1997. This recovery is shown spatially in the 1996 December-to-December panels of Figure 7. Cattle dipping for 12-months and removing cattle for 12 months suppressed hostseeking larvae to near zero. In 1997 populations of host-seeking larvae recovered from those treatments sequentially in association with favorable spring precipitation (Fig 6g, annotation 2), then hot and dry conditions during summer, which was followed by sufficient fall precipitation (Fig 6g, annotation 3). Populations of host-seeking larvae recovering from 12-month systematic cattle dipping recovered much faster and exceeded $8,000 /$ ha as compared to $4,000 /$ ha for the pasture vacation method (Fig 6g, annotation 3).

Treatment year 1997 began with the lowest host-seeking larval population at approximately 6,000/ha (Fig. 6d and h). This is shown spatially as the least dense panels for the pre-treatment 1997 December period in Figure 7. The three eradication methods suppressed the larval populations to near zero in 1997, but recovered through 1998 to above 9,000/ha. Recovery from the 9-month systematic dipping program was slower than that in the previous treatment years (Fig 6h, annotation 1). This could be attributed to the excessively cold winter of 1997. Relic CFT populations apparently benefitted from precipitation patterns in the fall of 1997 and the spring of 1998 (Fig 6h, annotation 2). Subsequent population declines in the summer due to heat and no precipitation were followed by substantial population increases above pretreatment levels (Fig 6h, annotation 3). This is reflected spatially in the series of progressive panels for 1997 in Figure 7.

Differences in overall treatment efficacy among the 9 scenarios based on the mean number of "host-seeking larval weeks" accumulated during the 2 years immediately following the week of treatment are summarized in Figure 8. Although the 3 eradication methods (DipNine, DipTwelve, CattleOff) all were statistically significantly different from each 
other ( $p<0.05)$, efficacies of the two methods involving treatment applications over a 12-month period (DipTwelve and CattleOff) were, for all practical purposes, essentially indistinguishable from one another (Fig. 8a). Differences among the 3 years (3 different temporal weather profiles) within eradication methods were statistically significantly different from each other (p $<0.05$ ) for the methods involving treatment applications over a 12-month period (DipTwelve and CattleOff), but not for the method involving treatment applications over a 9-month period (DipNine) (Fig. 8a). Relative relationships among the 9 scenarios were unaffected by changes in values of key model parameters (Fig. 8b). Not surprisingly, all of the parameter changes produced statistically significant differences in the mean number of accumulated "host-seeking larval weeks" under each of the eradication methods, with 2 exceptions. Differences between the version of the model in which $\mathrm{k}$ was set at $110 \%$ of its baseline value and the version of the model in which deer density was fixed at double its baseline value were not statistically significantly different from one another when simulating the scenario in which acaricides were applied to cattle every 2 weeks for 12 consecutive months in 1995 and when simulating the scenario in which acaricides were applied to cattle every 2 weeks for 12 consecutive months in 1996 (indicated by the arrows in Fig. 8b).

\section{Discussion}

Our model is the first attempt to address a knowledge gap in how the interactions of climate variation, cattle, and deer impact CFT eradication efforts in the U.S. as prioritized by Pérez de León et al. (2010). The majority of the relatively few studies that have used a spatiallyexplicit, individual-/agent-based model to investigate tick-host interactions have been focused on 3-host ticks (Wang et al. 2012; Wang et al. 2015; Wang et al. 2016). Wang et al. (2012) 
developed the first spatially explicit, individual-/agent-based, stochastic model that simulated the spatial-temporal dynamics of lone star ticks (Amblyomma americanum (L.)) in response to changes in climatic conditions, landscape structure, and host community composition in suburban area. Their model represented the influence of changes in host community characteristics on the maintenance of tick populations. These same authors (Wang et al. 2015) modified their earlier model (Wang et al. 2012) by adding the flexibility to represent shifts in the seasonal occurrence of fluctuations of host densities and by representing in more detail the movements of hosts as they collect and redistribute ticks across the simulated landscape. They found that abundances of active host-seeking ticks were affected primarily by the degree of cooccurrence of periods of high densities of unfed ticks and periods of high densities of hosts. Subsequently, Wang et al. (2016) modified the model of Wang et al. (2012) to examine the effects of changes in host density on the spatial-temporal prevalence of infected ticks within the landscape. They found that variation in simulated nymphal infection prevalence values could be explained by the fact that larval, nymphal, and adult tick loads were distributed differently among the different-sized hosts, each with their distinct range of movement and degree of variation in population size. The first spatially-explicit, agent-based CFT model was developed by Estrada-Peña et al. (2014). Their model, which represented deer movement based on graph theory, examined the efficacy of anti-tick vaccination of white-tailed deer in controlling CFT infestations using hypothetical buster vaccination schedules for individual animals. Their simulation results suggested that an anti-tick vaccination schedule on days 1 and 70 could be useful in preventing the re-introduction of CFTs into tick-free areas, however, vaccination schedules beyond this time frame produced minimal to no-control. 
Our present spatially-explicit, individual-based, stochastic model does not make precise predictions, but, rather, provides an exploratory tool to investigate climate-cattle-deer-CFTlandscape interactions in the permanent quarantine zone (Wang et al. 2012). Nonetheless, we believe that model performance is sufficient to further assess existing and/or hypothetical treatment applications directed at deer, and for evaluating integration of treatment tactics for both cattle and deer. Simulation results of baseline contributions of both host species to CFT populations and their responses to three official eradication protocols via dipping cattle in acaricide or by vacating infested premises are consistent with historic records of recrudescent infestations summarized by Pound et al. (2010). These simulations capture the complex interactions of seasonal and annual weather patterns with cattle and deer usage of diverse habitat types that drive CFT dispersal and subsequent off-host survivorship (Phillips et al. 2014). Simulation results suggest the existence of refugia for CFT in space and time that could sustain tick populations and compromise eradication efforts involving cattle-centric approaches. Simulation results also suggest that the success of treatment regimens in controlling CFT depends not only on the type of treatment application but also on the timing of applications relative to the CFT lifecycle, which, in turn, shifts in response to changing climatic conditions. Synchronizing applications to maintain high efficacy of the acaricides in cattle during climatically-driven periods of peak host-seeking larval activity seems particularly important.

Our detailed analysis of the simulated differences in post-treatment tick population recovery rates depending on the particular year of application (see Results section) emphasizes the importance of considering pre-treatment infestation levels and post-treatment climatic conditions, as well as spatial distributions of host-seeking larvae and potential hosts, when trying to identify the cause-effect relationships responsible for differences in treatment efficacies. 
Indeed, a unifying theme underlying the development and application of several previous tick population simulation models has been a focus on climate-tick-host-landscape interactions (e.g., Wang et al. 2012; Wang et al. 2015). Wang et al. (2012) examined the relative sensitivities of simulated densities of off-host lone star ticks (Amblyomma americanum) to changes in model parameters representing climatic conditions, landscape characteristics, and host densities and found that simulated densities were affected more by changes in climatic conditions. Wang et al. (2015) found that differences in simulated abundances of host-seeking lone star ticks among the various scenarios they investigated were due to system-level interactions of host availability with tick phenology, with the later driven primarily by climatic conditions.

The spatial and temporal rangeland-landscape use by cattle and deer in the thorn shrublands of south Texas has been the subject of investigations focused on animal production or conservation goals, and each one has relevance to CFT eradication issues (McMahan and Inglis 1974; Inglis et al. 1979; Cohen et al. 1989; Cooper et al. 2008). Differential preferences for forage or browse resources of cattle and deer create spatial layers of landscape use that can explain the resulting mosaic of CFT distribution and population densities. Interactions between deer and cattle also vary according to many factors including terrain topography and structure, pasture size, stocking density, and intensity of operation. For example, a comparison of shortduration, and continuous grazing systems on deer activity showed differences in home range and movement (Cohen et al. 1989). Permutations of these factors may explain why CFT infestations remain persistent where deer and cattle share rangeland landscapes. Treatment regimens involving cattle suppress the overall tick population, but refuge infestations enabled by deer provide the basis for reinfestation once treatments cease. 
Further ecological complexities exist that are not presently in the model and may be most helpful to consider in future simulations. Habitat heterogeneity and landscape fragmentation in the thorn-shrublands of south Texas are spatially and temporally complex. These are influenced by physical and natural factors, by changes in land management, and by intergenerational property transfer and change in land use. Populations of cattle and deer were held constant under continuous grazing in current simulations and would not capture changes due to births or deaths in reproductive cycles, or capture changes resulting from management decisions for animal production goals. We also recognize that the relative populations of cattle-to-deer vary considerably and those population structure differences in space and time will lead to different CFT-host-landscape outcomes. Disturbances created in the course of rounding-up and treating or inspecting cattle tend to temporarily push deer to adjoining pastures/properties (Hood and Inglis1974), further complicating the risks of tick dispersal and tick refugia. Localized populations of CFT sustained on wildlife have either stable, or diverse and changing gene pools arising from either long-sustained, or serially-re-infested premises, respectively, even in the context of eradication programs (De Meeûs et al. 2010; Busch et al. 2014).

Other wildlife species in the Texas-Mexico region are driving the need for novel tactics and strategies for CFT elimination. Besides deer, 6 additional species of native and exotic hoofstock present in the south Texas region were found to be infested with either $R$. annulatus or $R$. microplus as identified by the USDA, APHIS, National Veterinary Services Laboratory (Pound et al. 2010). One of these, nilgai, Boselaphus tragocamelus, is an exotic species belonging to the Bovidae family native to India that was successfully introduced to south Texas between 1930 and1941 (Moczygemba 2010; Sheffield 1983). Nilgai have become involved in CFT infestations in the transboundary region at the mouth of the Rio Grande, and in the Rio Grande valley of 
south Texas (Cardenas-Canales et al. 2011). Unchecked, the spread of CFT will increase economic and animal health burdens to producers, landowners, local communities and regulatory agencies (Anderson et al. 2010).

This situation emphasizes the urgent need for continued research to explore novel eradication schemes and to integrate tools like the model described here with other technologies as part of an adaptive strategy to keep the U.S. free of CFT in the face of global change (Pérez de León et al. 2012). As one example, the present model could be used to evaluate the proposal that cattle could function as a "sponge" or "trap" for CFT by using them as a tracer or sentinel species, thus combining systematic surveillance and treatment to sustain eradication in otherwise persistently-infested premises where deer and cattle coexist (Kistner and Hayes 1970; Pérez de León et al. 2010). Simulation of spatially-explicit chronologies of changes in vector density should suggest where and when monitoring and treatment efforts would be most effective, thus allowing the design and a priori testing of specific field sampling strategies in specific landscapes under specific conditions (Wang et al. 2016).

In closing, we would note that simulation models explicitly representing key processes by which control methods intervene in life cycles of target species are gaining recognition as being uniquely suited for a priori assessments of novel eradication schemes targeted at specific aspects of a vector's life cycle (Poché et al. 2016). Hopefully, our present model will be integrated into programs aimed at enhancing prevention, preparedness, and the management of CFT outbreaks in the U.S. (Pérez de León et al. 2012), and also will stimulate development and integration of similar models within control programs aimed at other vectors in the U.S. and elsewhere.

\section{Acknowledgements:}


Assistance of the Southern Regional Climate Center, Baton Rouge, Louisiana, USA, in providing weather data for Corpus Christi, Texas is greatfully acknowledged. This article reports the results of research only. Mention of a proprietary product does not constitute an endorsement or a recommendation by the USDA for its use. The USDA is an equal opportunity provider and employer. The research of Dr. Pérez de León is supported by appropriated funds for projects 3094-32000-039-00, 3094-32000-036-00, and 3094-32000-037-00. This research was also supported in part by Texas A\&M AgriLife Research Project TEX08911 and by a USDA, CSREES Grant 2010-65213-20554.

\section{References}

Anderson, D.P., A.D. Hagerman, P.D. Teel, G.G. Wagner, J. Outlaw and B.K. Herbst. 2010. Economic impact of expanded fever tick range. Research Report 10-2. College Station, TX: Agriculture and Food Policy Center, Texas A\&M AgriLife Research.

Archer, S., C. Scifres and C.R. Bassham. 1988. Autogenic succession in a subtropical savanna: Conversion of grassland to thorn woodland. Ecol. Monog. 58:111-127.

Aubry,P. and D.W. Geale. 2011. A review of bovine anaplasmosis. Transbound. Emerg. Dis. $58: 1-30$.

Barré, N., and G. Uilenberg. 2010. Spread of parasites transported with their hosts: case study of two species of cattle tick. Rev. Sci. Tech. 29:149-160.

Busch, J.D., N.E. Stone, R. Nottingham, A Araya-Anchetta, J. Lewis, C. Hochhalter, J.R. Giles, J. Gruendike, J. Freeman, G. Buckmeier, D. Bodine, R. Duhaime, R. Miller, R.D. Davey, P.U. Olafson, G.A. Scoles and D.M. Wagner. 2014. Widespread movement of invasive 
cattle fever ticks (Rhipicephalus microplus) in southern Texas leads to shared local infestations on cattle and deer. Parasites and Vectors 7:188 (16 pp).

Cardenas-Canales, E.M., J.A. Ortega-Santos, T.A. Campbell, Z. Garcia-Vazquez, A. CantuCovarrubias, J.V. Figueroa-Millan, R.W. DeYoung, D.G. Hewitt, and F.C. Bryant. 2011. Nilgai antelope in northern Mexico as a possible carrier for cattle fever ticks and Babesia bovis and Babesia bigemina. J. Wildlife Diseases 47:777-779.

Cohen, W.E., D.L. Drawe, F.C. Bryant and L.C. Bradley. 1989. Observations on white-tailed deer and habitat response to livestock grazing in south Texas. J. Range Management 42(5):361-65

Cooksey, L.M., R.B. Davey, E.H. Ahrens and J.E. George. 1989. Suitability of white-tailed deer as hosts for cattle fever ticks (Acari: Ixodidae). J. Med. Entomol. 26:155-158.

Cooper, S.M., H.L. Perotto-Baldivieso, J.K. Owens, M.G. Meek and M. Gigueroa-Pagan. 2008. Distribution and interaction of white-tailed deer and cattle in a semi-arid grazing system. Agric., Ecosys and Environ. 127:85-92.

Currie, C. 2013. Influence of white-tailed deer on cattle fever tick eradication efforts in southern Texas. Kingsville, TX: Dissertation. Texas A\&M University.

Daynes, P. and J. Gutierrez. 1980. Variations saisonnieres de l'activite parasitaire de la tique de betail Boophilus microplus (Acari, Ixodidae) en Nouvelle-Caledonie. Rev. Elev. Med. Vet. Pays Trop. 33:305-310.

De Meeûs T1, Koffi BB, Barré N, de Garine-Wichatitsky M, Chevillon C. 2010. Swift sympatric adaptation of a species of cattle tick to a new deer host in New Caledonia. Infect. Genet. Evol. 10:976-983. 
Esteve-Gassent MD, Pérez de León AA, Romero-Salas D, Feria-Arroyo TP, Patino R, CastroArellano I, Gordillo-Pérez G, Auclair A, Goolsby J, Rodriguez-Vivas RI, Estrada-Franco JG. 2014. Pathogenic Landscape of Transboundary Zoonotic Diseases in the Mexico-US Border Along the Rio Grande. Front Public Health. 2:177.

Estrada-Pena, A., D. Carreon, C. Almazan and J. de la Furente. 2014. Modeling the impact of climate and landscape on the efficacy of white-tailed deer vaccination for cattle tick control in northeastern Mexico. PLOS One. 9:e102905

Estrada-Pena, A., Z. Garcia and H. Fragoso Sanchez. 2006. The distribution and ecological preferences of Boophilus microplus (Acari: Ixodidae) in Mexico. Exp. Appl. Acarology 38:307-316.

Estrada-Pena, A. and J.M. Venzal. 2006. High-resolution predictive mapping for Boophilus annulatus and B. microplus (Acari: ixodidae) in Mexico and Southern Texas. Vet. Parasitol. 142:350-358.

George, J.E. 1990. Wildlife as a constraint to the eradication of Boophilus spp. (Acari: Ixodidae). J. Agric. Entomol. 7:119-125.

Giles, J.R., A.T. Peterson, J.D. Busch, P.U. Olafson, G.A. Scoles, R.B. Davey, J.M. Pound, D.M. Kammlah, K.H. Lohmeyer, and D.M. Wagner. 2014. Invasive potential of cattle fever ticks in the southern United States. Parasit. Vectors. 7:189

Graham, O.H. and J.L. Hourrigan. 1977. Eradication programs for the arthropod parasites of livestock. J. Med. Entomol. 13:629-658.

Gray, J.H., R.L. Payne, G.O. Schubert and W.H. Garnett. 1979. Implications of white-tailed deer in the Boophilus annulatus eradication program, pp 506-515. In: Proc. $83^{\text {rd }}$ Meeting US AHA, 28 October-2 Nov 1979, San Diego, CA 
Grear JS, Koethe R, Hoskins B, Hillger R, Dapsis L, Pongsiri M. 2014. The effectiveness of permethrin-treated deer stations for control of the Lyme disease vector Ixodes scapularis on Cape Cod and the islands: a five-year experiment. Parasit Vectors. 7:292.

Grimm, V., U. Berger, F. Bastiansen, S. Eliassen, V. Ginot, J. Giske, J. Goss-Custard, T. Grand,

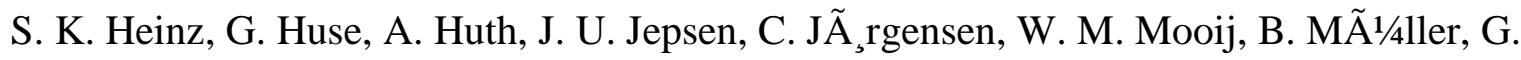
Peâ€ ${ }^{\mathrm{TM}}$ er, C. Piou, S. F. Railsback, A. M. Robbins, M. M. Robbins, E. Rossmanith, N.

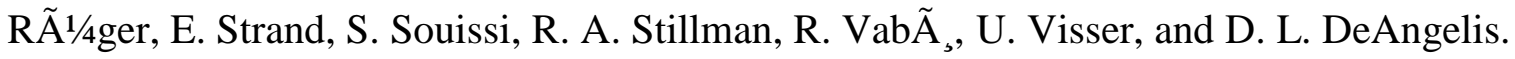
2006. A standard protocol for describing individual-based and agent-based models. Ecological Modelling 198:115-126.

Grimm V, U. Berger, D.L. DeAngelis, J.G. Polhill, J. Giske, S.F. Railsback. 2010. The ODD protocol: a review and first update. Ecological modelling. 221:2760-2768.

Hellickson, M.W., T.A. Campbell, K.V. Miller, R.L. Marchinton and C.A. DeYoung. 2008 Seasonal ranges and site fidelity of adult male white-tailed deer (Odocoileus virginianus) in southern Texas. The Southwestern Nat. 53:1-8.

Hood, R.E. and J.M. Inglis. 1974. Behavioral responses of white-tailed deer to intensive ranching operations. J. Wildlife Management 38:488-498.

Howery, L.D., F.D. Provenza, R.E. Banner and C.B. Scott. 1996. Differences in home range and habitat use among individuals in a cattle herd. Appl. Anim. Behav. Sci. 49:305-320.

Hygnstrom, S., D. Drake, T. Van Deelen and S. Vantassel. 2014. Managing overabundant whitetailed deer: is it time to consider regulated commercial harvest? Outlooks on Pest Management, 25:11-16.

Inglis, J.M., R.E. Hood, B.A. Brown and C.A. DeYoung. 1979. Home range of white-tailed deer in Texas coastal prairie brushland. J. Mammology 60:377-389. 
Kie, J.G. and R.T. Bowyer. 1999. Sexual segregation in white-tailed deer: Density-dependent changes in use of space, habitat selection, and dietary niche. J. Mammology 80:1004-1020.

Kistner TP, Hayes FA. 1970. White-tailed deer as hosts of cattle fever-ticks. J Wildl Dis. 6:437440.

Lohmeyer, K.H., J.M. Pound, M.A. May, D.M. Kammlah and R.B. Davey. 2011. Distribution of Rhipicephalus (Boophilus) microplus and Rhipicephalus (Boophilus) annulatus (Acari: Ixodidae) infestations detected in the United States along the Texas/Mexico border. J. Med. Entomol. 48:770-774.

McMahan, C.A. and J.M. Inglis. 1974. Use of Rio Grande Plain brush types by white-tailed deer. J. Range Mgmt. 27:369-374.

Miller RJ, Davey RB, George JE. 2005. First report of organophosphate-resistant Boophilus microplus (Acari: Ixodidae) within the United States. J. Med. Entomol. 42:912-917.

Miller, R., A. Estrada-Peña, C. Almazán, A. Allen, L. Jory, K. Yeater, M. Messenger, D. Ellis and A.A. Pérez de León. 2012. Exploring the use of an anti-tick vaccine as a tool for the intergrated eradication of the cattle fever tick, Rhipicephalus (Boophilus) annulatus. Vaccine. 30:5682-5687.

Miller RS, Farnsworth ML, Malmberg JL. 2013. Diseases at the livestock-wildlife interface: status, challenges, and opportunities in the United States. Prev. Vet. Med. 110:119-132.

Moczygemba, J.D. 2010. Movements of nilgai antelope (Boselaphus tragocamelus) in southern Texas. Kingsville, TX: Thesis. Texas A\&M University.

Mount, G.A., D.G. Haile, R.B. Davey and L.M. Cooksey. 1991. Computer simulation of Boophilus cattle tick (Acari: Ixodidae) population dynamics. J. Med. Entomol. 28:223-240. 
Pérez de León, A.A., Strickman, D.A., Knowles, D.P., Fish, D., Thacker, E.L., de la Fuente, J., Krause, P.J., Wikel, S.K., Miller, R., Wagner, G.G., Almazan, C., Hillman, R., Messenger, M.T., Ugstad, P.O., Duhaime, R.A., Teel, P.D., Ortega-Santos, A., Hewitt, D.G., Bowers, E.J., Bent, S.J., Cochran, M.H., McElwain, T.F., Scoles, G.A., Suarez, C.E., Davey, R.B., Freeman, J.M., Lohmeyer, K.H., Li, A.Y., Guerrero, F., Kammlah, D.M., Phillips, P.L., and Pound, J.M. 2010. One Health approach to identify research needs in bovine and human babesioses: workshop report. ParasitVectors 3: 36-46.

Pérez de León, A.A., P.D. Teel, A.N. Auclair, M.T. Messenger, F.D. Guerrero, G. Schuster and R.J. Miller. 2012. Integrated strategy for sustainable cattle fever tick eradication in USA is required to mitigate the impact of global change. Frontiers in Physiology. 3(3)doi:

10.3389/fphsy.2012.00195

Pérez de León, A.A., E. Vannier, C. Almazán and P.J. Krause. 2014a. Tick- borne protozoa.

Biology of Ticks, D. E. Sonenshine and R. M. Roe (Eds.), Oxford University Press, New York, Vol. 2, pp. 147-179.

Pérez de León, A. A., Teel, P.D., Li, A., Ponnusamy, L., and Roe, R.M. 2014b. Advancing integrated tick management to mitigate burden of tick-borne diseases. Outlooks Pest Manag. 25:382-389.

Phillips, P.L., J.B. Welch and M. Kramer. 2014. Development of a spatially targeted field sampling technique for the southern cattle tick, Rhipicephalus microplus, by mapping whitetailed deer, Odocoileus virginianus, habitat in South Texas. J. Insect Sci. 14:1-21.

Poché, D.M., W.E. Grant, and H.-H. Wang. 2016. Visceral leishmaniasis on the Indian subcontinent: Modelling the dynamic relationship between vector control schemes and vector 
life cycles. PLOS Neglected Tropical Diseases. 10: e0004868. DOI:

10.1371/journal.pntd.0004.

Popham, T.W. and G.I. Garris. 1991. Considerations when modeling alternative eradication strategies for Boophilus microplus (Canestrini) (Acari: Ixodidae) in Puerto Rico. J. Agric. Entomol. 8: 271-289.

Pound, J.M., J.E. George, D.M. Kammlah, K.H. Lohmeyer, and R.B. Davey. 2010. Evidence for role of white-tailed deer (Artiodactyla: Cervidae) in epizootiology of cattle ticks and southern cattle ticks (Acari: Ixodidae) in reinfestations along the Texas/Mexico border in South Texas: A review and update. J. Med. Entomol. 103:211-218.

Pound, J.M., K.H. Lohmeyer, and R.B. Davey, L.A. Soliz, and P.U. Olafson. 2012. Excluding feral swine, javelinas, and raccoons from deer bait stations. Human-Wildlife Interactions, 6:169-177.

Rue, L.L. 1978. The deer of North America. Crown Publishing Co., N.Y.

Sheffield, W.J. 1983. Kleberg studies in natural resousrces: The Nilgai antelope in Texas. Texas Agricultural Experiment Station, Texas A\&M University. 100 pp.

Urdaz-Rodríguez J, Fosgate G, Alleman AR, Rae O, Donovan A, Binford M, Zaragoza A, Melendez P. 2012. Association between ecological factors and the presence of Rhipicephalus (Boophilus) microplus larvae in Puerto Rico. Exp Appl Acarol. 58:145-157.

Vercauteren, , K. C., C. W. Anderson, T. R. Van Deelen, D. Drake, W. D. Walter, S. M. Vantassel, and S. E. Hygnstrom. 2011. Regulated commercial harvest to manage overabundant white-tailed deer: An idea to consider? Wildl. Soc. Bull. 35:185-194. 
Wang, H.-H., W.E. Grant, P.D. Teel. 2012. Simulation of climate-host-parasite-landscape interactions: a spatially-explicit model for ticks (Acari: Ixodidae). Ecological Modelling 243: $42-62$.

Wang, H.-H., W.E. Grant, P.D. Teel. 2015. Simulation of climate-tick-host-landscape interactions: Effects of shifts in the seasonality of host population fluctuations on tick densities. Journal of Vector Ecology 40(2): 247-255.

Wang, H.-H., W.E. Grant, P.D. Teel, S.A. Hamer. 2016. Tick-borne infectious agents in nature: Simulated effects of changes in host density on spatial-temporal prevalence of infected ticks. Ecological Modelling 323: 77-86. 


\section{Figure Legends}

Figure 1. Conceptual model representing the effects of interactions among climate variation, habitat heterogeneity, and host community on the population dynamics of the southern cattle tick (Rhipicephalus (Boophilus) microplus). Lines illustrate two pathways by which ticks can obtain the blood meals necessary to complete their life cycle.

Figure 2. Map of adjoining principalities along the transboundary region of Texas, USA/Mexico with historical infestations of the southern cattle fever tick (Rhipicephalus (Boophilus) microplus).

Figure 3. Overview of the sequence of events and processes involved in the execution of the model to simulate spatial and temporal population responses of the southern cattle fever tick (Rhipicephalus (Boophilus) microplus).

Figure 4. Summary of temporal responses of simulated southern cattle fever tick (Rhipicephalus (Boophilus) microplus) populations to weather dynamics. The left column (a-d) shows simulation values for the 7-year time period, and in the right column expanded details are provided for 1996 (e-h) in which resolution of monthly and seasonal influences can be evaluated. (a) Seven-year (1994-2000) time series of input data representing weekly air temperatures (T, in ${ }^{\circ} \mathrm{C}$, dashed line), saturation deficits ( $\mathrm{S}$, in millibars, grey line), and index values based on precipitation ( $\mathrm{P}$, in $\mathrm{cm}$, black line) near Corpus Christi, Texas, USA used in the simulations conducted during model evaluation. (b) The resulting densities of host-seeking larvae in simulations during which both cattle (Bos taurus) and white-tailed deer (Odocoileus virginianus) 
were present $(\mathrm{C}+\mathrm{D}$, dashed line), only cattle were present $(\mathrm{C}$, grey line), and only deer were present (D, black line). Notations 1-7 in (b) identify populations of host-seeking larvae that exceeded 8000 larvae/ha and declined below 2000 larvae/ha. (c) The resulting mean numbers of adult ticks on cattle in simulations during which both cattle and deer were present $(\mathrm{C}+\mathrm{D}$, dashed line), and only cattle were present (C, grey line). (d) The resulting mean numbers of adult ticks on deer in simulations during which both cattle and deer were present $(\mathrm{C}+\mathrm{D}$, dashed line $)$, and only deer were present ( $\mathrm{D}$, black line).

Figure 5. Spatial responses of southern cattle fever tick (Rhipicephalus (Boophilus) microplus) populations on a simulated landscape in a typical baseline simulation. Maps indicate (a) distribution of the three habitat types (mesquite savanna, green; mixed brush savanna, red; open rangeland, blue), levels of habitat use by (b) cattle (Bos taurus) and (c) white-tailed deer (Odocoileus virginianus), as well as the resulting densities of host-seeking larvae (darker shading indicates heavier use or higher density) (d) in simulations during which both cattle and deer were present, (e) in simulations during which only cattle were present, and (f) in simulations during which only deer were present.

Figure 6. Summary responses of simulated southern cattle fever tick (Rhipicephalus (Boophilus) microplus) populations to three tick eradication protocols (removing cattle for 12 months, cattle off; dipping cattle in acaricide every 2 weeks for 9 months, dip 9; dipping cattle in acaricide every 2 weeks for 12 months, dip 12) on the densities of host-seeking larvae in the simulated system initiated in 1995 (a), 1996 (b), and 1997 (c). Vertical dashed lines are provided only to 
aid in associating the applications of tick control strategies chronologically with climatic conditions. Annotations $(1,2,3)$ in (a) - (c) provide reference points for ticks recovery.

Figure 7. Responses of southern cattle fever tick (Rhipicephalus (Boophilus) microplus) populations to three tick eradication protocols on the spatial distributions of host-seeking larvae (darker shading indicates higher density) during simulations in which the indicated strategy (removing for 12 months, cattle off; dipping cattle in acaricide every 2 weeks for 9 months, dip 9; dipping cattle in acaricide every 2 weeks for 12 months, dip 12) was applied during the indicated year (before-1995, during-1996, or after-1997 a particularly unfavorable year for ticks). Maps show distributions the month before (December) and 6, 12, 18, and 24 months after treatment application. Red dots illustrate the presence of animal hosts cattle (Bos taurus) and/or white-tailed deer (Odocoileus virginianus). Spatial distributions of the three habitat types (mesquite savanna, mixed brush savanna, open rangeland) were identical to those shown in Figure 5 for all of these simulations; thus spatial distributions of levels of habitat use by both cattle and white-tailed deer were similar to those shown in Figure 5 during all of these simulations.

Figure 8. Differences among the indicated eradication scenarios for Rhipicephalus (Boophilus) microplus in the overall presence of host-seeking larvae during the 2 years following treatment application, as indicated by the mean number of "host-seeking larval weeks" accumulated during this period. (a) Results generated using the version of the model with baseline parameter values. (b) Results generated using each of the additional 9 versions of the model in which we represented the landscape as consisting of (1) all good, (2) all fair, 
and (3) all poor habitat; fixed deer densities at (4) 1.235 (double baseline), (5) 0.30875 (half baseline), and (6) 0 individuals / ha; and set the value of $\mathrm{k}$ at (7) 90 (90\% of baseline), (8) 110 (110\% of baseline), and (9) 120 (120\% of baseline). Arrows indicate the only two versions of the model that were not statistically significantly different from one another. 


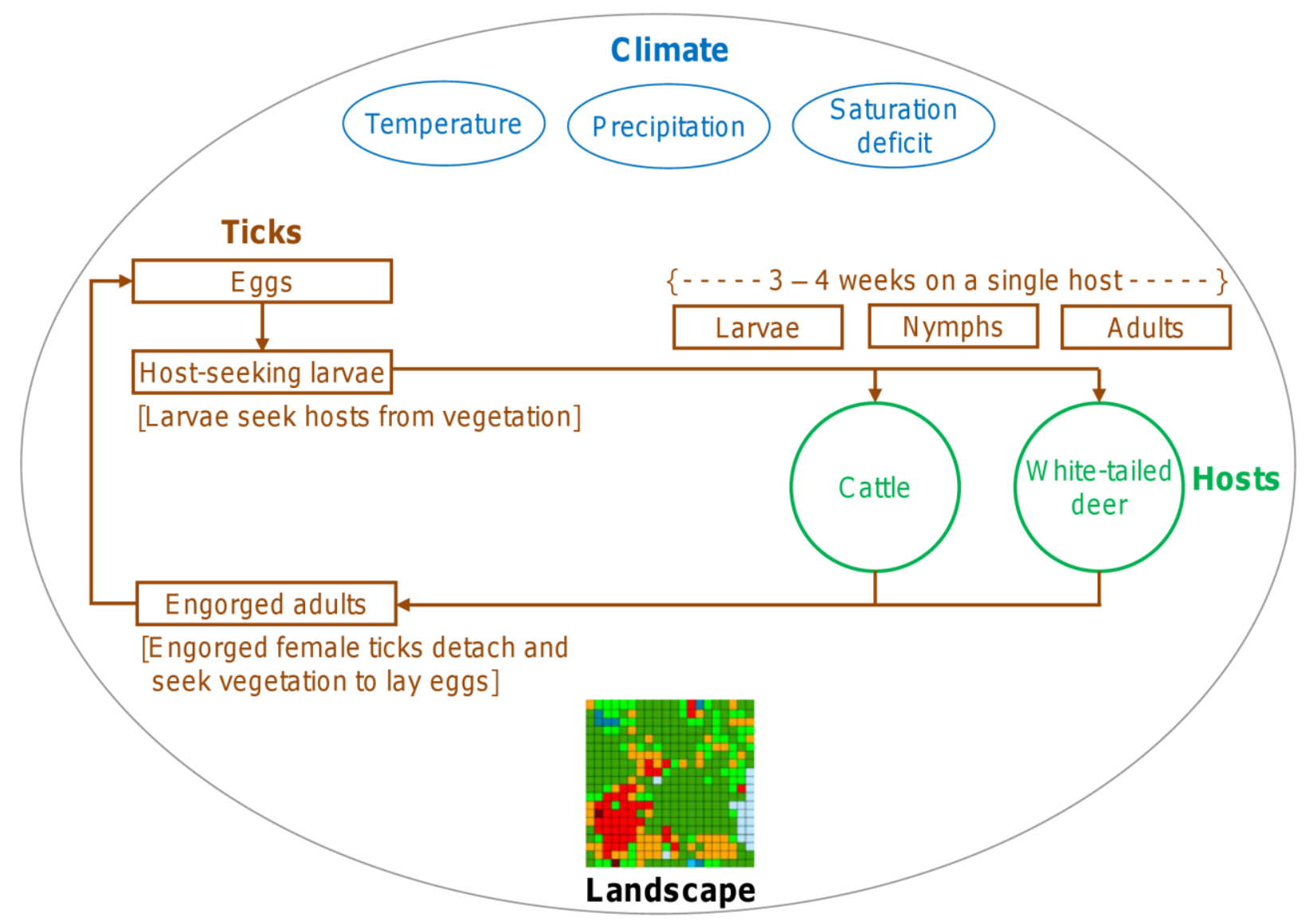




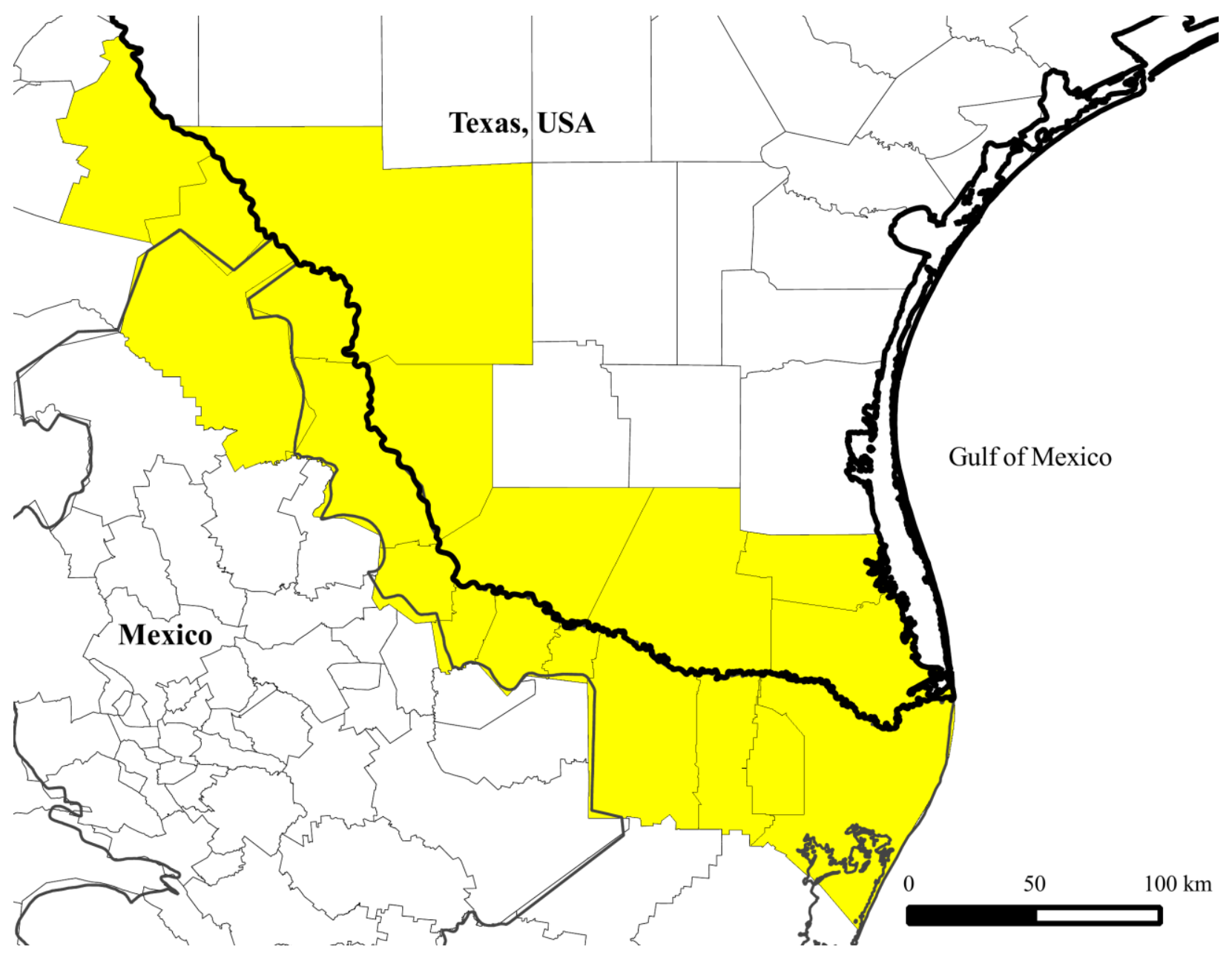




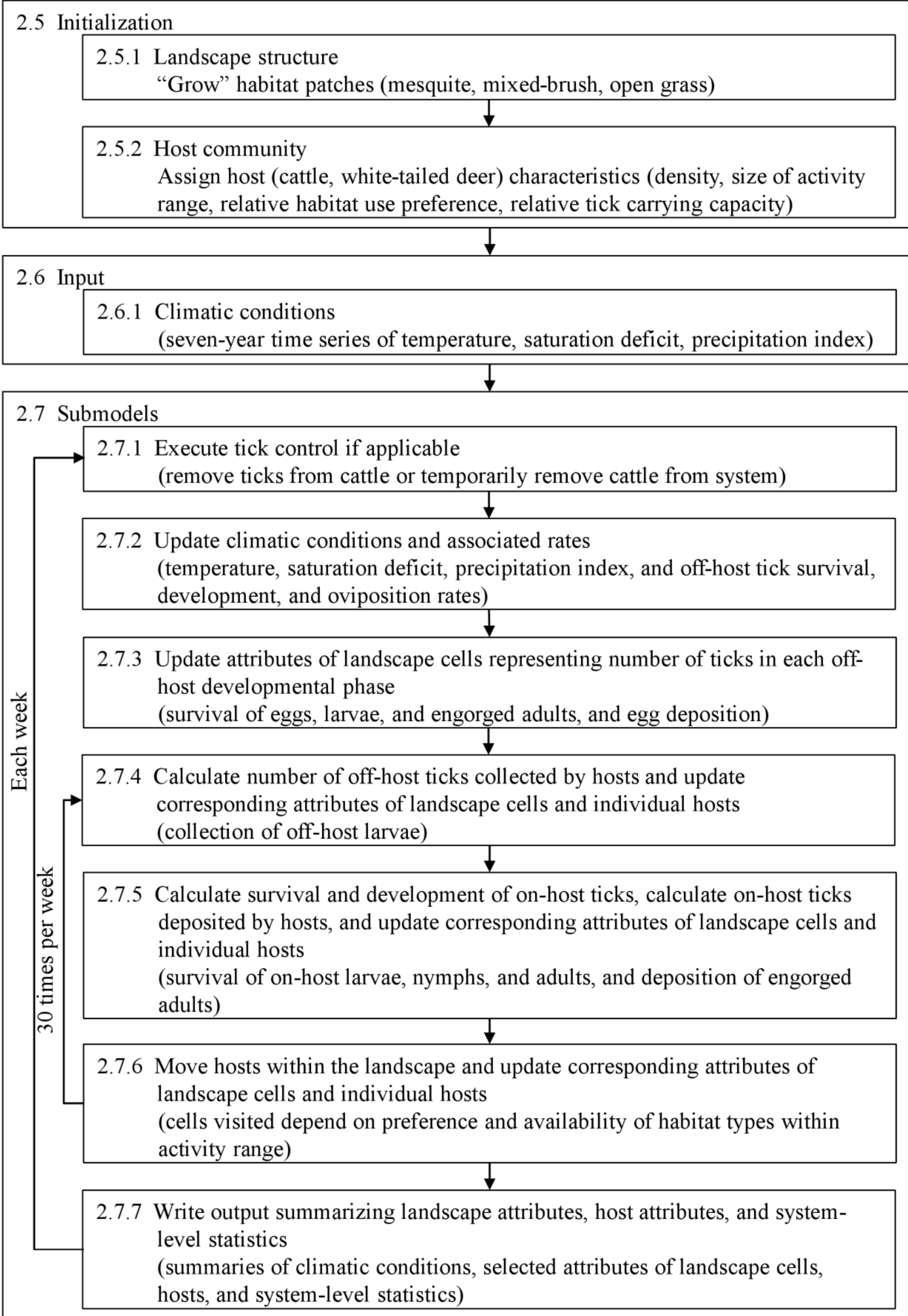


(a)

(b)

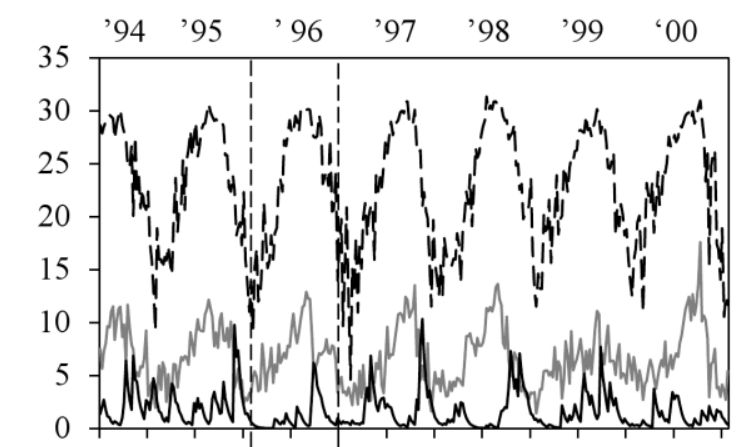

(c)

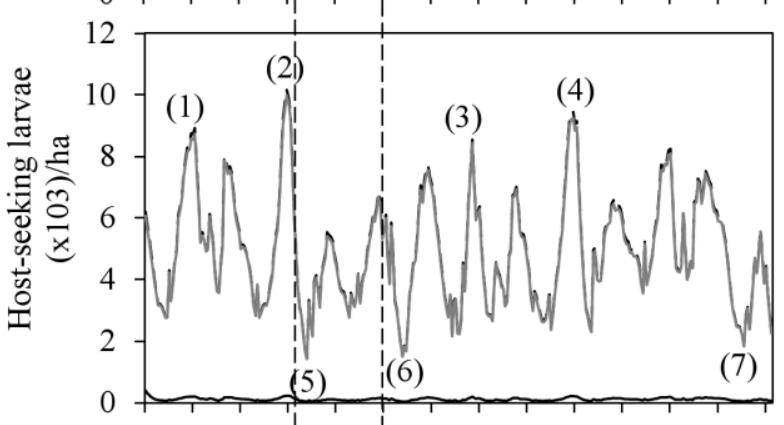

c)

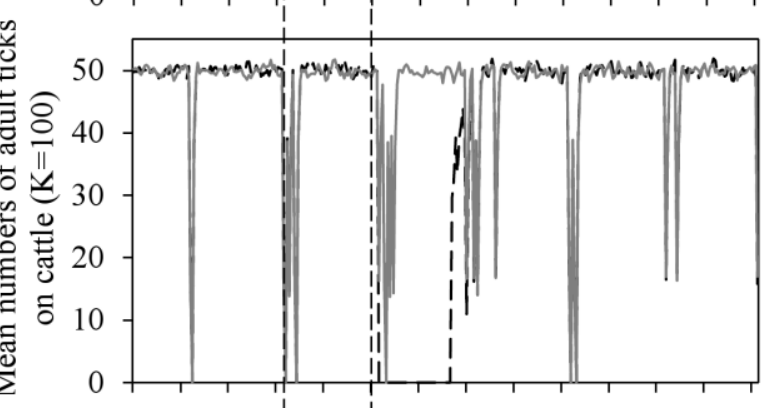

(d)

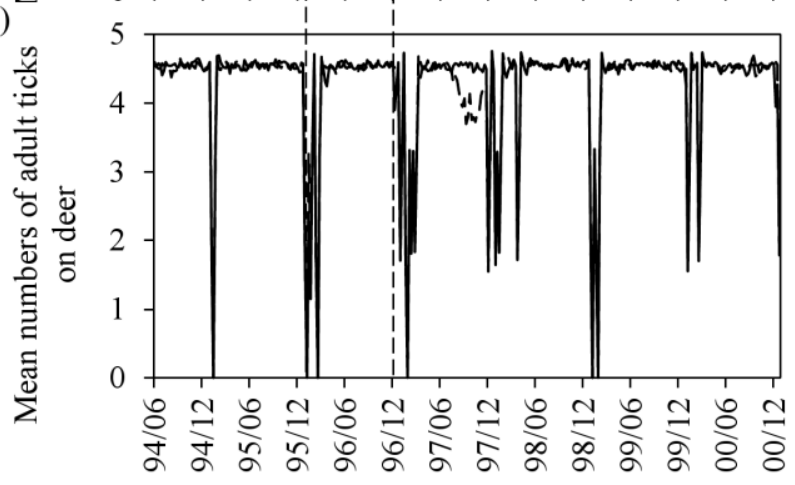

(e)

(f)

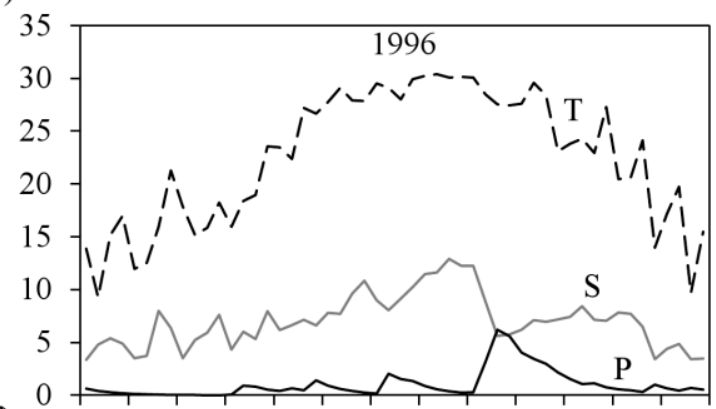

(f) 8

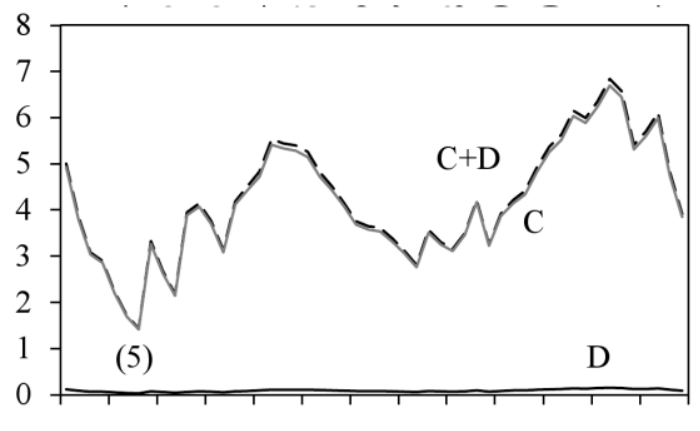

(g)

(h)

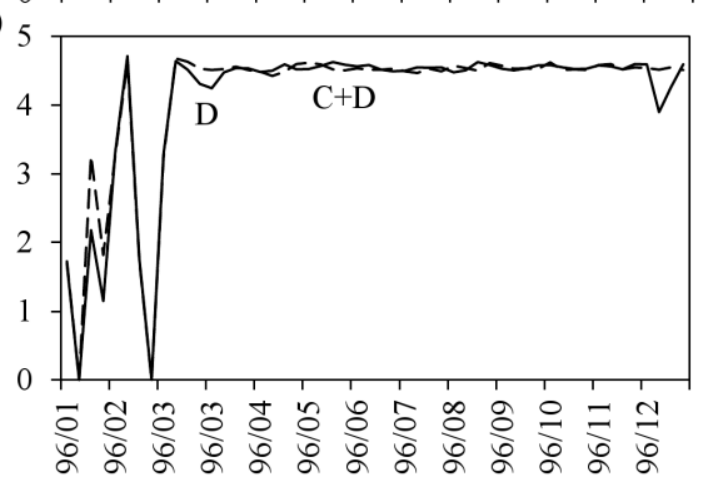


(a)

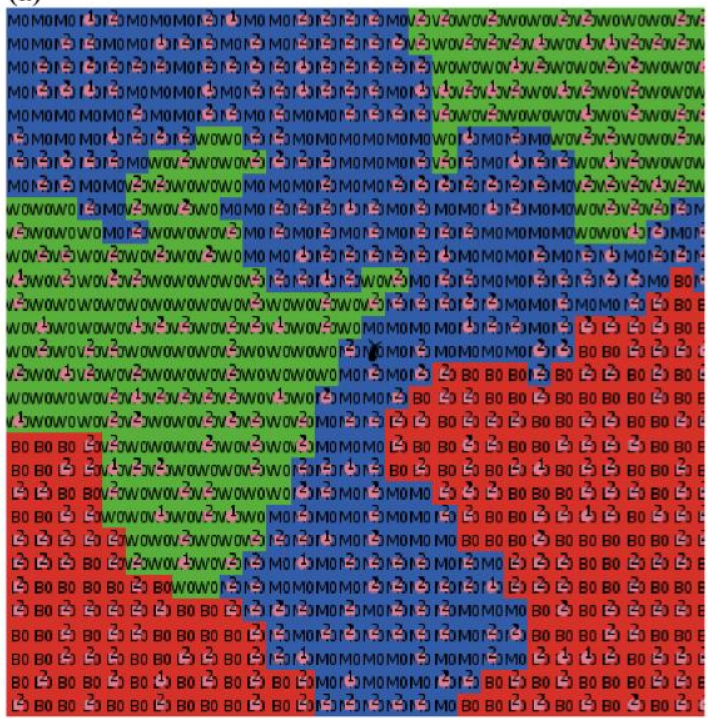

(b)

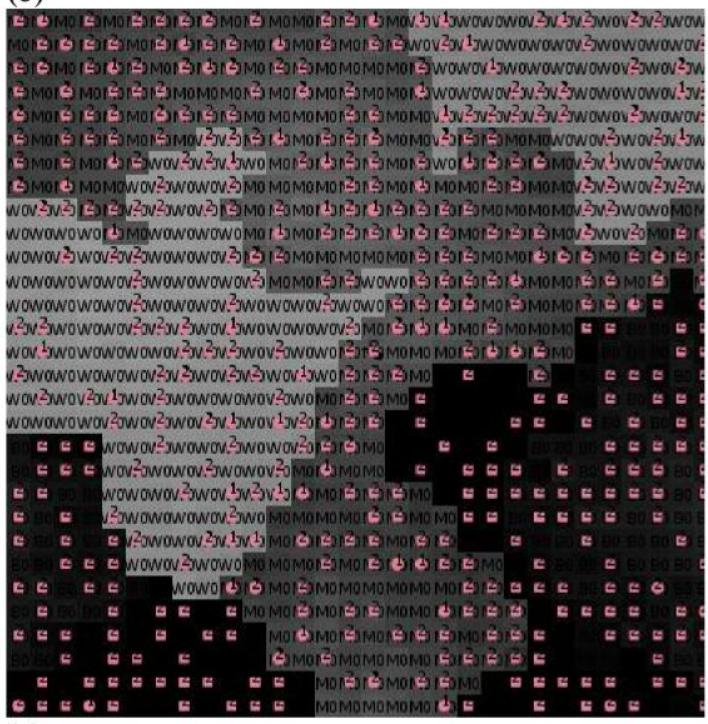

(c)

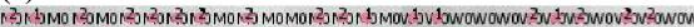

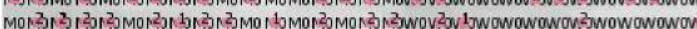

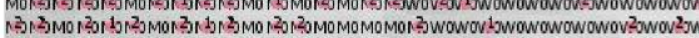

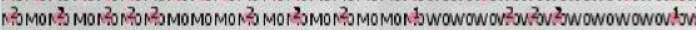

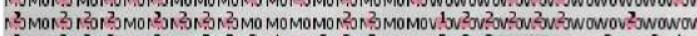

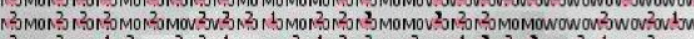

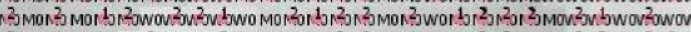

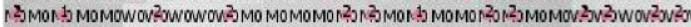

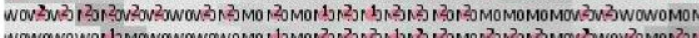

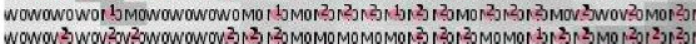

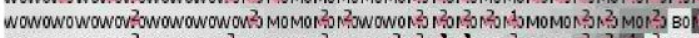

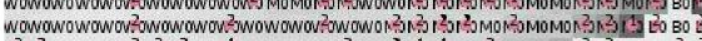

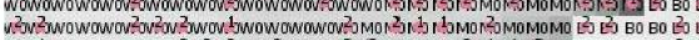
WOV b

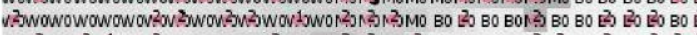

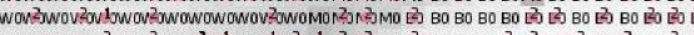

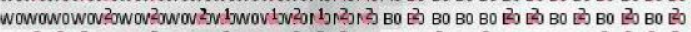

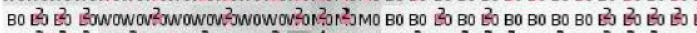

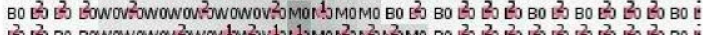
EO EO BO BOWOWOWOV.

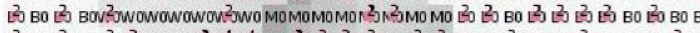

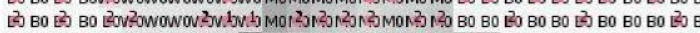

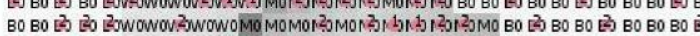

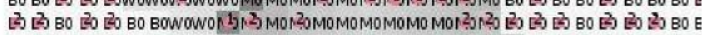

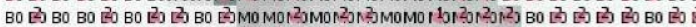

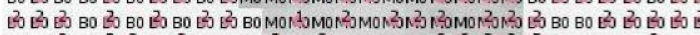

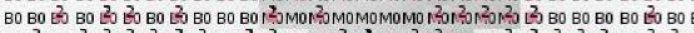

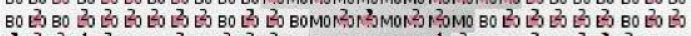

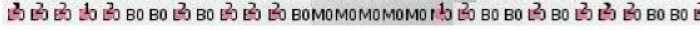

(d)

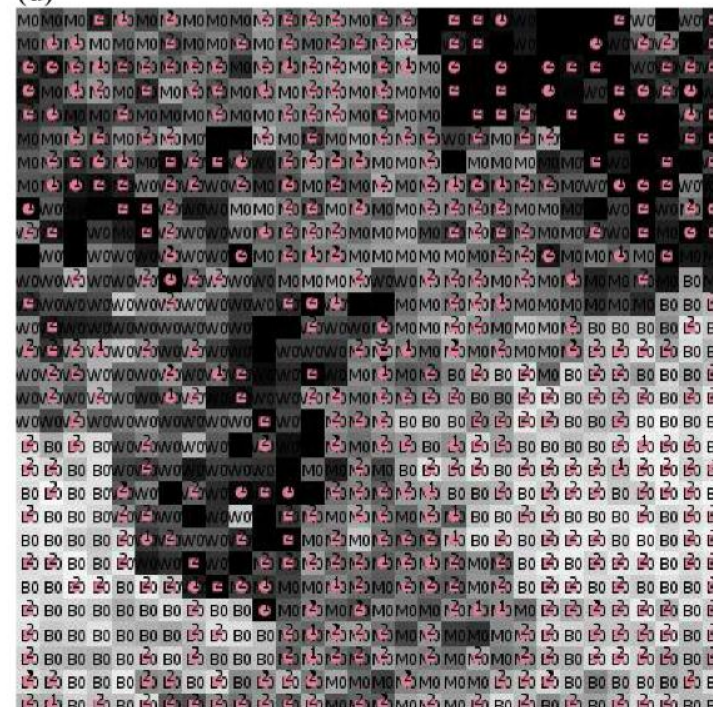

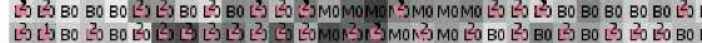
(e)

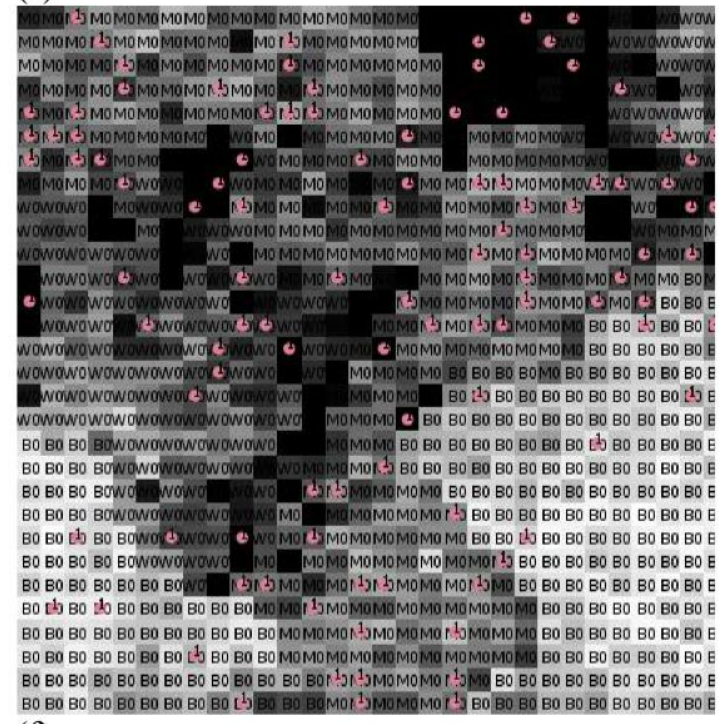
(f)

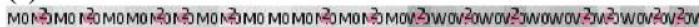

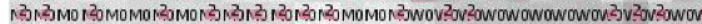

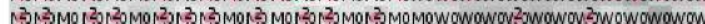

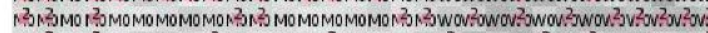

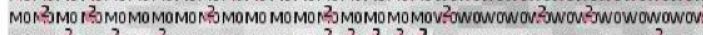

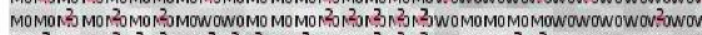

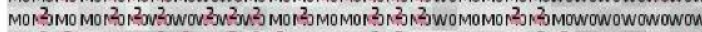

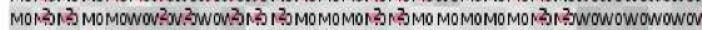

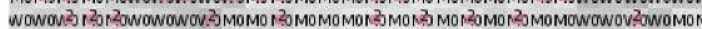

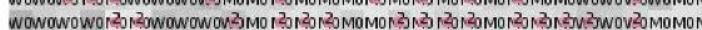

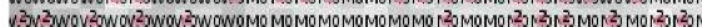

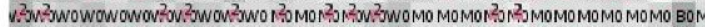

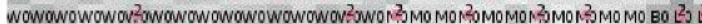

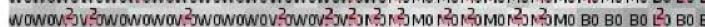

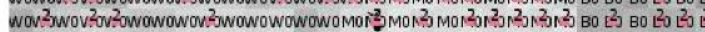

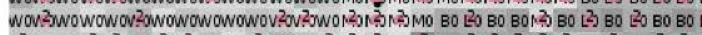

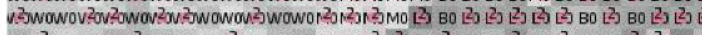

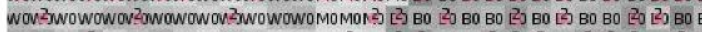

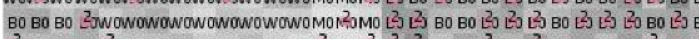

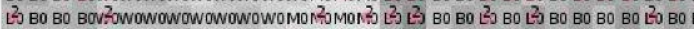

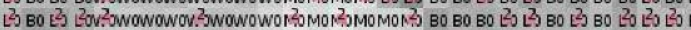
$L^{2} 3$ BO L3 BOW:JWOWON

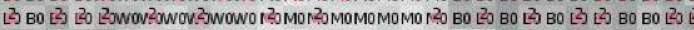

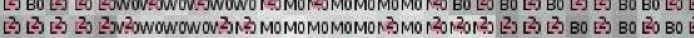
BO BO BO 20 BO EO BOWOV.

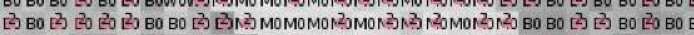

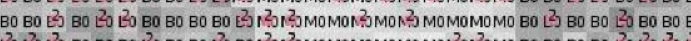

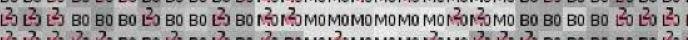

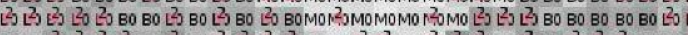

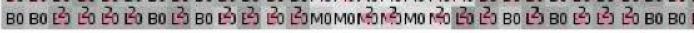



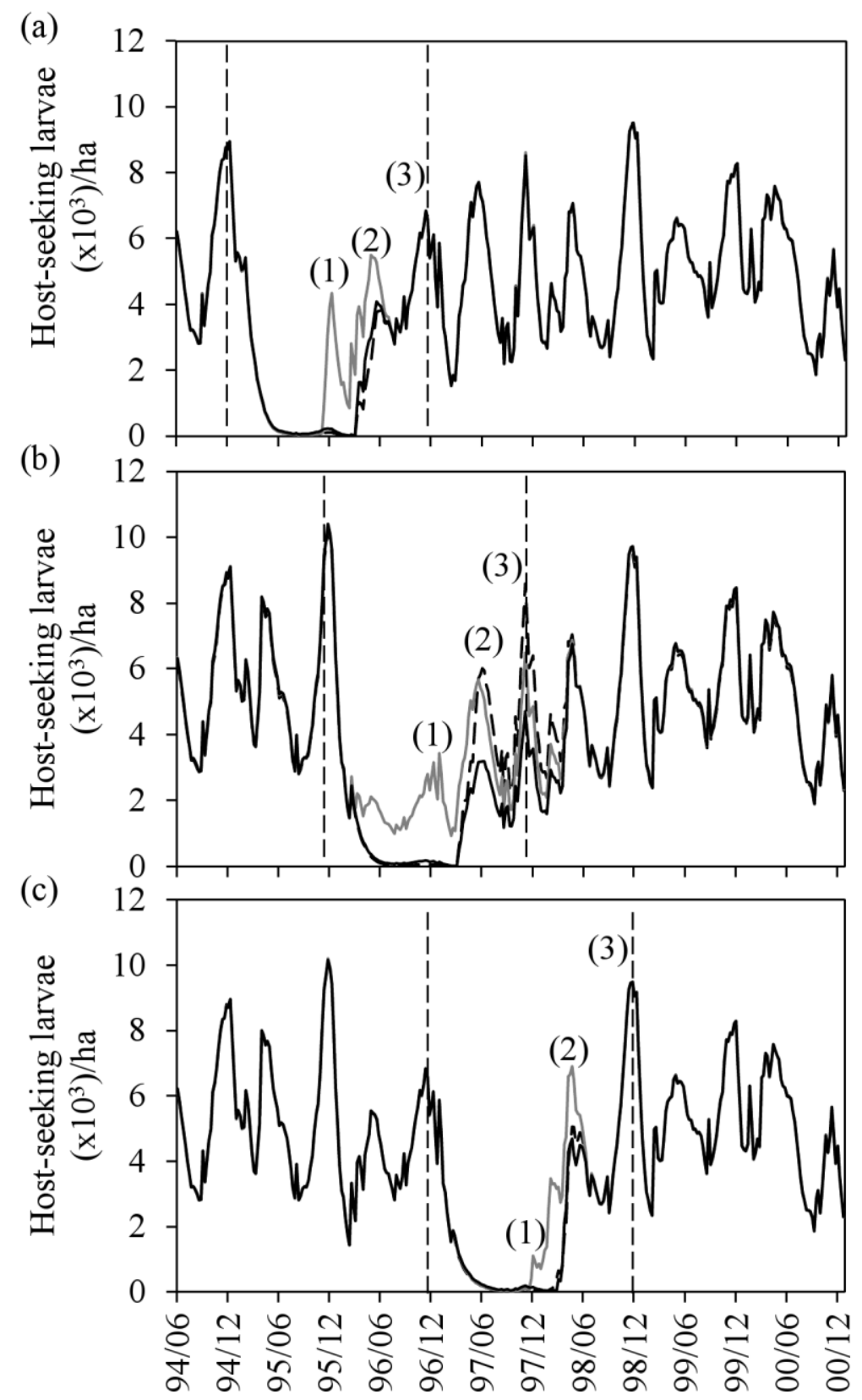


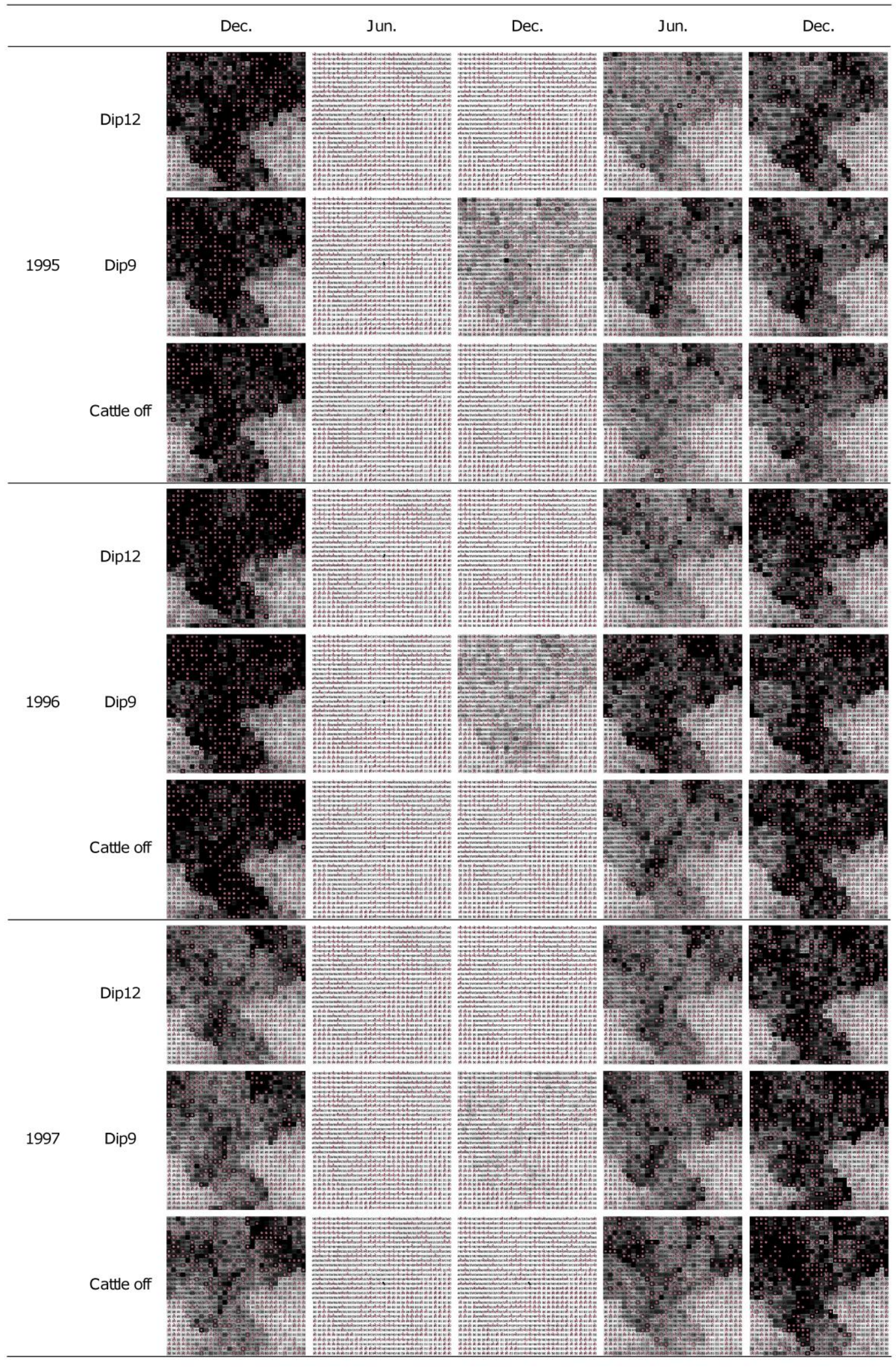


(a)

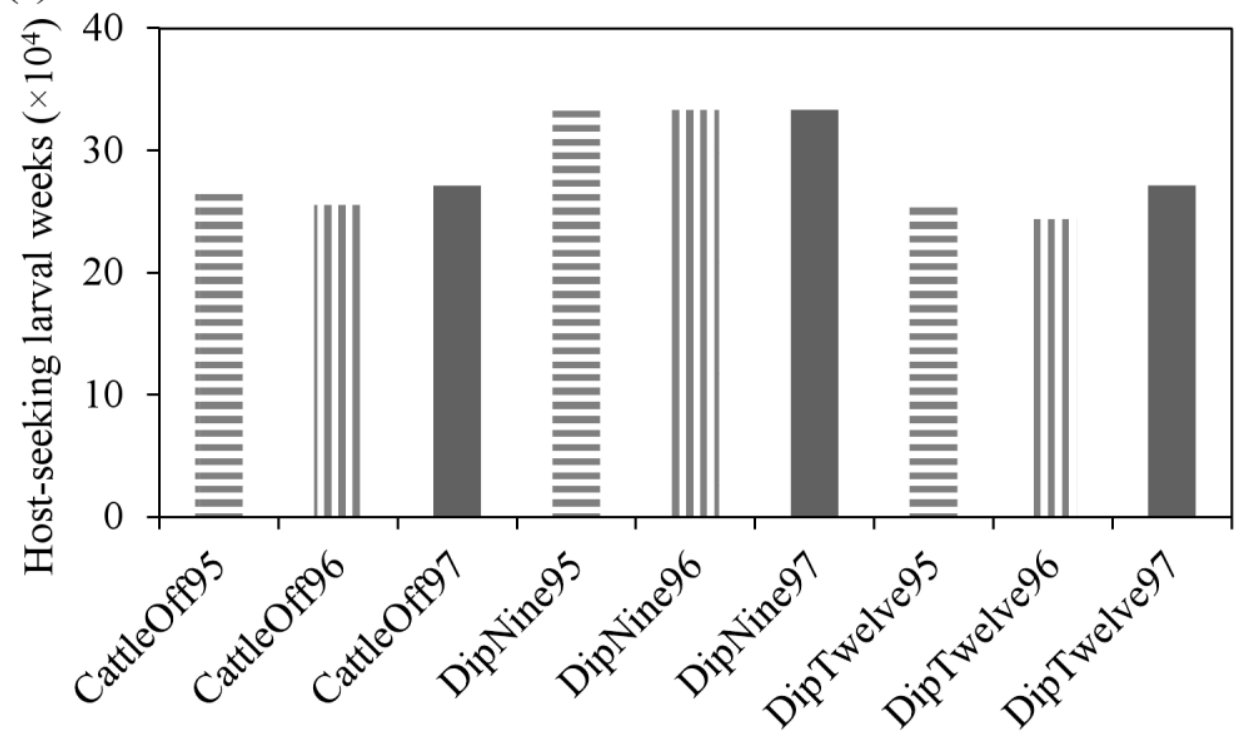

(b)
Baseline
(1) LandGFP 100
(2) LandGFP 010
(3) LandGFP 001
(4) $\square$ Deer Den. 1.235
(5) $\square$ Deer Den. 0.30875
(6) Deer Den. 0
(7) $\square \mathrm{k} 90$
(8) $\square \mathrm{k} 110$

(9) $\square \mathrm{k} 120$

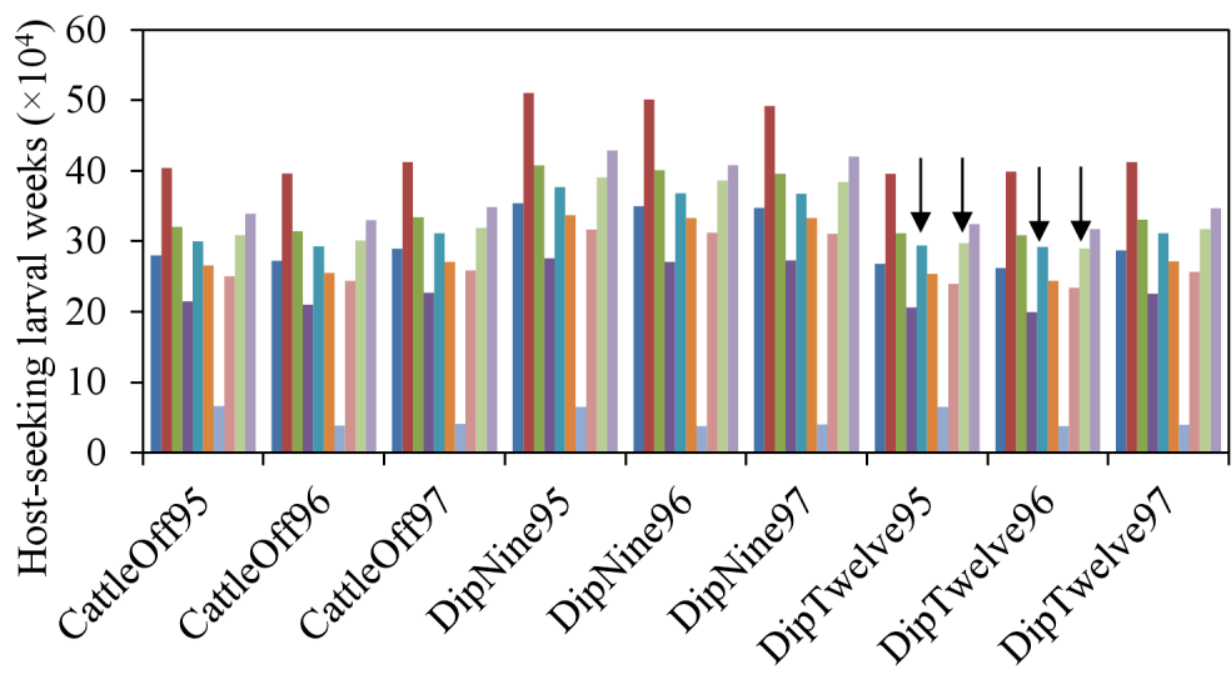

